This manuscript has been peer reviewed and has been accepted for publication in Journal of Geophysical Research - Planets. When assigned, the final typeset version of this manuscript will be available via the publication DOI link on this page. 


\title{
Experimental Determination of Mantle Solidi and Melt Compositions for Two Likely Rocky Exoplanet Compositions
}

\author{
K. K. Brugman ${ }^{1 *}$, M. G. Phillips ${ }^{1 \dagger}$, C. B. Till ${ }^{1}$ \\ ${ }^{1}$ School of Earth and Space Exploration, Arizona State University, Tempe, AZ USA \\ Corresponding author: Kara Brugman (kbrugman@carnegiescience.edu; @karabrug) \\ *Now at Earth \& Planets Laboratory, Carnegie Institution for Science, Washington, D.C. \\ USA \\ ${ }^{\dagger}$ Now at United States Geological Survey, Moffett Field, CA USA
}

\section{Key Points:}

- First of their kind experiments examine phase equilibria and melt compositions for exoplanet silicate mantles at terrestrially relevant $f \mathrm{O}_{2}$.

- The mineralogy and melts are similar to those of Earth's mantle. One composition melts at conditions more likely to produce magma oceans.

- Results can be used to calibrate future exoplanet models for volatile solubility, volcanic atmosphere contributions, and crust composition. 


\section{Abstract}

For rocky exoplanets, knowledge of their geologic characteristics such as composition and mineralogy, surface recycling mechanisms, and volcanic behavior are key to determining their suitability to host life. Thus, determining exoplanet habitability requires an understanding of surface chemistry, and understanding the composition of exoplanet surfaces necessitates applying methods from the field of igneous petrology.

Piston-cylinder partial melting experiments were conducted on two hypothetical rocky exoplanet bulk silicate compositions. $\mathrm{HEX} 1$, a composition with molar $\mathrm{Mg} / \mathrm{Si}=$ 1.42 (higher than bulk silicate Earth's $\mathrm{Mg} / \mathrm{Si}=1.23$ ) yields a solidus similar to that of Earth's undepleted mantle. However, $\mathrm{HEX} 2$, a composition with molar $\mathrm{Ca} / \mathrm{Al}=1.07$ (higher than Earth $\mathrm{Ca} / \mathrm{Al}=0.72$ ) has a solidus with a slope of $\sim 10^{\circ} \mathrm{C} / \mathrm{kbar}$ (versus $\sim 15^{\circ} \mathrm{C} / \mathrm{kbar}$ for Earth) and as result, has much lower melting temperatures than Earth. The majority of predicted adiabats point toward the likely formation of a silicate magma ocean for exoplanets with a mantle composition similar to HEX2. For adiabats that do intersect HEX2's solidus, decompression melting initiates at pressures more than 4x greater than in the modern Earth's undepleted mantle. The experimental partial melt compositions for these exoplanet mantle analogs are broadly similar to primitive terrestrial magmas but with higher $\mathrm{CaO}$, and for the $\mathrm{HEX} 2$ composition, higher $\mathrm{SiO}_{2}$ for a given degree of melting.

This first of its kind exoplanetary experimental data can be used to calibrate future exoplanet petrologic models and predict volatile solubilities, volcanic degassing, and crust compositions for exoplanets with bulk compositions and $f \mathrm{O}_{2}$ similar to those explored herein. 


\section{Plain Language Summary}

The composition of rocky exoplanets can be approximated, to first order, from the composition of the stars they orbit. In this work, we conducted experiments to determine the types of minerals found in the interior of two hypothetical exoplanets that orbit stars with compositions different from our star, and the magma compositions produced from melting them. Our results suggest that in many ways exoplanets with these potential compositions have melting behavior similar to that of the Earth's interior. A key difference is that one composition produced melt at much lower temperatures than Earth, such that the exoplanet may form a magma ocean early in its history or begin melting at depths greater than are common in Earth today. These results provide constraints for modeling geologic processes on exoplanets and their ability to support life; this study underlines the need for further experimentation of this kind. The geochemical models that can be derived from this and similar studies will allow us to better interpret the data returned by satellites that will observe exoplanets in the near future. 


\section{Introduction}

Since the discovery of the first exoplanets in the early 1990s (Mayor \& Queloz, 1995; Wolszczan \& Frail, 1992), questions about extra-solar planets have focused on their potential to support life. Over 4200 exoplanets have been identified in the last 30 years, with active missions such as NASA's Transiting Exoplanet Survey Satellite (TESS) and the University of Liège's Transiting Planets and Planetesimals Small Telescope (TRAPPIST) aiming to double this number in the next few years. To date, investigations of exoplanets have primarily utilized methods from the fields of astronomy and geophysics; knowledge of exoplanets is overwhelmingly limited to parameters that can be calculated from astronomical observations (e.g., mass and radius). These data have allowed for the classification of exoplanets by their size and stellar irradiance (Fulton et al., 2017; Weiss et al., 2018), but scientists have lamented a limited ability to produce models of exoplanet atmospheres and interior structure that include chemical information, as there is a dearth of empirical data to quantify silicate mantle compositions beyond that of Earth and our solar system (Dorn et al., 2018; Hu et al., 2012; Kite et al., 2020; Schwieterman et al., 2018; Unterborn \& Panero, 2019). As scientists endeavor to answer questions about exoplanets' compositions, interior structures, and near surface conditions with regards to their suitability for life, incorporating knowledge from a broad array of Earth and planetary science disciplines becomes critical.

Most exoplanets from the California-Kepler Survey, a collection of stellar and planetary data for Kepler candidate exoplanets (Johnson et al., 2017; Petigura et al., 2017), are less than 4 Earth radii in size with a gap in the distribution at $\sim 1.5-2$ Earth radii, regardless of the size of the host star (Fulton et al., 2017; Martinez et al., 2019; 
Owen \& Wu, 2013). This gap separates small exoplanets into two populations: largerradius exoplanets more likely to have thick gas envelopes and smaller-radius exoplanets more likely to be rocky with thin atmospheres, the latter of which are sometimes referred to as "super-Earths" (Fulton et al., 2017; Martinez et al., 2019; Valencia et al., 2006). Super-Earths are attractive targets for study not only due to their potential to orbit in their stars' habitable zone (the orbital region where liquid water is possible on a planetary surface) (Kane et al., 2016; Kasting et al., 1993; Kopparapu et al., 2014) but because of their abundance (Bryson et al., 2020; Fulton et al., 2017; Johnson et al., 2017). For exoplanets likely to be rocky, knowledge of geologic characteristics such as composition and mineralogy, surface recycling mechanisms (e.g., plate tectonics versus stagnant lid), and volcanic behavior are key to determining their suitability to host life. Thus, the application of methods from the fields of igneous petrology and geochemistry are critical to advance investigation of these terrestrial exoplanets.

Volcanism — specifically the melting of a planet's mantle to form magma-is how a planet makes new crust. For example, on Earth, continental crust is built at volcanic arcs and intraplate continental hot spots (e.g., Yellowstone) and oceanic crust is built at mid-ocean ridges, or at loci of intraplate volcanism (e.g., Hawaii). Volcanism has occurred during the last $\sim 4 \mathrm{Ga}$ on almost all of the rocky bodies in the solar system, including planets that likely did not have Earth-like plate tectonics; even Vesta and Ceres have likely experienced some volcanism (e.g., Byrne, 2019). Efforts have been made to quantify the rates of volcanic activity on exoplanets (e.g., Quick et al., 2020 and references therein), but even on an exoplanet without Earth-like plate tectonics, new crust can be produced through decompression melting, cooling and degassing of a magma 
ocean, or impact-initiated melting. Once a planet has formed a surface crust, most subsequent planetary melt-producing processes cause partial melting of the planet's mantle with some remaining solid residue. These partial melts coalesce, rise to the surface, and may erupt to become the planet's youngest crust. This is the style of melting relevant for the largest portion of a planet's lifespan — after the planet's initial formation and accretion and/or any magma ocean stage.

Unfortunately, existing geochemical and petrologic models for melt formation and mineral equilibria are not calibrated for rocky exoplanet compositions; these models were created to work with solid rock (bulk silicate) compositions of Earth or other terrestrial planets in our solar system, all of which are to first order tied to the composition of the Sun (e.g., Bond et al., 2010; Hinkel \& Unterborn, 2018; Plotnykov \& Valencia, 2020 and references therein). Planetary formation models interpret solar nebulae to comprise all of the elemental building blocks for the resulting star and its orbiting bodies, as established by the correlation between the compositions of condensed planetary material (i.e., carbonaceous chondrites) and the solar photosphere (Feldman, 1992). Similarly, the rocky portion of exoplanets can be related to the composition of their host stars. Thus, when considering the composition of the Sun in relation to the profusion of known stellar compositions (Hinkel et al., 2014; Unterborn \& Panero, 2019), it is not surprising that existing models for Earth would not be well suited for all of the exoplanets that orbit such a diverse population of stars. Updating or creating new geochemical models for super-Earth exoplanets requires experimental data on exoplanetary (and correspondingly extrasolar) chemical compositions. 
Experimental igneous petrology has been used to study melting on our solar system's planets and moons and has led to insights such as redox conditions, degree of differentiation, melt compositions, location of solidi, magma sources, and planetary cooling rates for these bodies (e.g., Filiberto, 2014; Grove \& Krawczynski, 2009; Kiefer et al., 2015, 2015; Krawczynski \& Grove, 2012; Namur et al., 2016; Putirka, 2016; Vander Kaaden et al., 2017; Wadhwa, 2008). Only recently have workers begun to apply concepts from experimental mineralogy and petrology to exoplanets, studies which thus far have focused mostly on Si-C planets and high pressure mineralogy (e.g., Daviau et al., 2019; Duffy \& Smith, 2019; Hakim et al., 2018, 2019; Miozzi et al., 2018; Nisr et al., 2017).

Here we use established techniques from the field of experimental igneous petrology to produce the first empirical data on upper mantle phase relations and melting on silicate super-Earth type exoplanets, which is needed to begin to close this knowledge gap and ultimately build better geochemical models for application to exoplanetary systems. We present the experimentally determined solidi, mineral modes, melting reactions, and partial mantle melt compositions for two hypothetical super-Earth type exoplanets. Our new data may be used to calibrate future geochemical models for exoplanets, as constraining the composition of exoplanet partial mantle melts is crucial to understanding element cycling from subsurface to surface, weathering on the exoplanet's surface, and the outgassing that contributes to secondary atmospheres.

\section{Methods}




\subsection{Selection of starting compositions}

The range of possible silicate exoplanet compositions can be assessed by examining the composition of known stars in our galaxy. Stellar compositions can be used as a first order proxy to the bulk silicate composition of an orbiting exoplanet (e.g., Bond et al., 2010; Hinkel \& Unterborn, 2018; Young et al., 2014). Stellar compositions vary significantly relative to the Sun, particularly in $\mathrm{Mg}, \mathrm{Fe}, \mathrm{Al}, \mathrm{Ca}$, and $\mathrm{Si}$, elements critical in rock-forming minerals (Bond et al., 2010; Hinkel et al., 2014). For example, the Sun has an Mg/Si molar ratio of 1.05 (Asplund et al., 2005) while the known stars in the Milky Way cover a broad range of molar $\mathrm{Mg} / \mathrm{Si}$, the bulk of which are between $0.7-$ 1.6 (Bond et al., 2010 and references therein). These deviations could result in silicate mantles whose characteristics, such as mantle mineral assemblages, solidi, and phase relationships, are markedly different than Earth. A basic appraisal of the breadth of possible exoplanet silicate mantle compositions can be achieved by comparing stellar compositions from which Fe has been subtracted to simulate core differentiation (Fig. 1, black circles).

However, stellar compositions should only be used as a guide. Observations of stellar elemental abundances are not absolute-measurements vary depending on the element and the methods employed to obtain and reduce a given dataset (Hinkel et al., 2016; Jofré et al., 2015). Furthermore, the actual composition of a rocky exoplanet's mantle is expected to deviate significantly from the star depending on the exoplanet's formation history and core composition (e.g., Bond et al., 2010; Plotnykov \& Valencia, 
manuscript submitted to JGR: Planets Special Issue Exoplanets: The Nexus of Astronomy and Geoscience

2020; Wang et al., 2018 and references therein). This is illustrated in Figure 1 by comparing the Sun's composition (yellow star; Asplund et al., 2005) to its calculated derivative bulk silicate planet (yellow circle) and the actual composition of Earth's undepleted mantle (blue diamond; Hart \& Zindler, 1986). Due to the non-unique link between the composition of a star and an orbiting rocky planet, the experimental starting compositions herein are not intended to directly simulate specific exoplanets. Instead, starting compositions were selected to establish relevant experimental calibration points for rocky exoplanets that are outside the compositional space of Earth and within the likely range of exoplanet compositions but not so foreign as to produce a $\mathrm{Si}-\mathrm{C}$ mineral assemblage.

The two selected hypothetical exoplanet mantle compositions (Table 1) help constrain a range of likely exoplanet bulk silicate compositions; they bracket Earth's bulk mantle composition in $\mathrm{Mg} / \mathrm{Si}$ while maintaining approximately equal $\mathrm{Fe} / \mathrm{Mg}$ (Fig. 1). The first hypothetical exoplanet starting composition (HEX1) was generated by adjusting the undepleted Earth mantle composition to produce a molar $\mathrm{Mg} / \mathrm{Si}$ ratio of 1.42 (Table 1), and represents exoplanet compositions with $\mathrm{Mg} / \mathrm{Si}$ ratios greater than Earth's undepleted mantle $(\mathrm{Mg} / \mathrm{Si}=1.23$; Hart \& Zindler, 1986). The second hypothetical exoplanet starting composition (HEX2) has a lower Mg/Si than that of Earth (0.95 vs. 1.23), but a higher molar Ca/Al ratio (1.07 vs. 0.72; Hart \& Zindler, 1986), similar to a region of composition space where pyroxene and other Ca-bearing phases may be more prevalent (Table 1; Carter-Bond et al., 2012).

\subsection{Experimental procedure}


All preparation and experiments were conducted at the Experimental Petrology and Igneous processes Center (EPIC) at Arizona State University (ASU). Starting mixes were produced from high purity oxide and carbonate powders and were ground in an agate mortar for two hours under ethanol. All $\mathrm{Fe}$ was added as $\mathrm{Fe}_{2} \mathrm{O}_{3}$ powder. The mixes, which included $\mathrm{Na}$ as $\mathrm{Na}_{2} \mathrm{CO}_{3}$ and $\mathrm{K}$ as $\mathrm{K}_{2} \mathrm{CO}_{3}$, were then decarbonated in a box furnace at $850^{\circ} \mathrm{C}$. The resulting compositions (Table 1) were analyzed on the EPMA according to the procedure in Section 2.3 after glassing the starting mixes. To do this, starting mix powder was mixed with polyvinyl alcohol and hung in the hotspot of a 1-atm vertical furnace using $0.005^{\prime \prime} \mathrm{Pt}_{30} \mathrm{Rh}_{70}$ wire. Mixes were brought to $1600^{\circ} \mathrm{C}$ for 30 minutes and then were quenched by passing a current through the wire to drop the sample into a container of water. HEX2 produced a pure glass following this procedure, but HEX1 failed to fully glass and so the actual HEX1 bulk composition was calculated via estimates of the modal $\%$ of crystals that formed, according to the guidance of Reid (1985) and Terry \& Chilingar (1955).

For the piston-cylinder experiments, approximately $0.03 \mathrm{~g}$ of starting mix was pressed into $\mathrm{Au}_{80} \mathrm{Pd}_{20}$ capsules that were triple-crimped and welded using a PUK TIG welder with a tungsten electrode under Ar gas. Experiments were conducted under nominally anhydrous conditions (no volatiles were added to the starting mix). Capsules were reweighed to check for mass loss or gain that may have occurred during welding, then checked for leakage by soaking in acetone for $10+$ minutes before weighing a third time. Any capsules that had changed mass were discarded and not used for experiments. 
Experiments were conducted in an end-loaded solid-medium piston-cylinder apparatus from Rockland Research (Boyd \& England, 1960) with automated pressure and temperature control, following the assembly arrangement and the heating and pressurization procedure of Médard and Grove (2006). To summarize, the 1/2" experimental assembly consisted of a $\mathrm{Pb}$-foil-wrapped sintered $\mathrm{BaCO}_{3}$ pressure sleeve; $\mathrm{MgO}$ spacers and thermocouple shield; an alumina ring and thermocouple sheath; and a graphite furnace and base. The intrinsic oxygen fugacity $\left(f \mathrm{O}_{2}\right)$ of the piston-cylinder assembly utilized for these experiments was determined to be $\mathrm{FMQ}+1$ by a prior study in the same laboratory (Iacovino et al., 2020) and thus is taken to be the estimated $f \mathrm{O}_{2}$ for these experiments. Using the model of Kress and Carmichael (1991) this equates to an expected $\mathrm{Fe}^{2+/ 3+}$ of $\sim 3.7$ in the experimental products. The $\mathrm{BaCO}_{3}$ pressure medium was found to have no pressure correction through calibration against the albite $=$ jadeite + quartz and $\mathrm{Ca}$-tschermak pyroxene $=$ anorthite + gehlenite + corundum reactions $($ Hays, 1966; Longhi, 2005). Pressure errors were determined to be $\pm 0.5 \mathrm{kbar}$ by a prior study in the same laboratory (Iacovino et al., 2020). Temperature was controlled with a Eurotherm 2404 to $\pm 20{ }^{\circ} \mathrm{C}$ and monitored using a Type $\mathrm{D} \mathrm{W}{ }_{3 \%} \mathrm{Re} / \mathrm{W}_{25 \%} \% \mathrm{Re}$ thermocouple accurate to $\pm 10^{\circ} \mathrm{C}$ (Médard \& Grove, 2006), with a temperature correction of $18-39^{\circ} \mathrm{C}$ independently calculated for each experiment depending on the geometry of the capsule and assembly. The degree of temperature correction was determined by spinel growth temperature calibration experiments conducted following the methodology of Watson et al. (2002).

Experiments were pressurized to $10 \mathrm{kbar}$ at room temperature then heated at $\sim 100^{\circ} \mathrm{C} / \mathrm{min}$ to $865^{\circ} \mathrm{C}$. If the target pressure was above $10 \mathrm{kbar}$, pressure was increased to 
the final experimental pressure during a six-minute dwell time. The piston-cylinder was then heated to the final experimental temperature. We conducted piston-cylinder experiments at $10-20 \mathrm{kbar}$ and $1100-1450^{\circ} \mathrm{C}$ with run durations of $24-72$ hours (Table 2). To mitigate the nucleation of crystals upon quenching, experiments were "pressure quenched" by simultaneously turning off heat and releasing pressure on the piston (Krawczynski \& Grove, 2012; Putirka et al., 1996).

\subsection{Analytical procedure}

The experimental charges were prepared for analysis by cutting each capsule in half longitudinally with a low-speed saw in order to analyze a section most representative of any possible variation due to small changes in temperature across the charge. One half of the capsule was vacuum-impregnated in epoxy and the other half was preserved for future analysis, if needed. Mounts were polished using diamond suspension pastes, carbon coated, and then analyzed using energy-dispersive X-ray spectroscopy (EDS) and wavelength-dispersive X-ray spectroscopy (WDS) on the JXA-8530F electron probe micro-analyzer (EPMA) at ASU's Eyring Materials Center, with the exception of experiment R137 which was analyzed on the JXA-8530F at the Carnegie Institution for Science's Earth \& Planets Laboratory. All analyses used an accelerating voltage of $15 \mathrm{kV}$ and beam current of $15 \mathrm{nA}$. Beam sizes were $1 \mu \mathrm{m}$ for minerals and $1-5 \mu \mathrm{m}$ for HEX1 melt and 5-10 $\mu \mathrm{m}$ for HEX2 melt. Time-dependent intensity (TDI) corrections were applied to melt analyses to mitigate migration of light elements away from the electron beam, however usually this correction did not have a statistically significant effect on the measurements. 


\section{Results}

\subsection{Demonstration of equilibrium}

Mineral phases in all of the reported experiments are compositionally homogenous throughout each charge and free of reaction rims. Experiments were considered unsuccessful if they failed mass balance calculations or lost $>6 \% \mathrm{Fe}$. Unsuccessful experiments were excluded from the results and discussion below with the exception of experiment R39 which lost $>10 \%$ Fe and was only used to confirm the location of the solidus (Table 2, Fig. 2A), the boundary in pressure-temperature space between regions wherein a material is entirely solid and wherein some melt can exist.

The bulk $\mathrm{Na}_{2} \mathrm{O}$ content for each starting mix is low at $\leq 0.27 \mathrm{wt} \%$ (Table 1 ). Mass balance calculations determined that some experiments included in the results experienced loss of $\mathrm{Na}_{2} \mathrm{O}>10 \%$ (Fig. S1) that is not correlated with pressure $(P)$ or temperature $(T)$, nor does it appear that the Na alloyed with the $\mathrm{Au}_{80} \mathrm{Pd}_{20}$ capsule. This loss is likely responsible for the uncertainty in the phase percentage calculations (Table 2). The $\mathrm{Na}_{2} \mathrm{O}$-bearing phases in the experiments are clinopyroxene and melt; orthopyroxene $\mathrm{Na}_{2} \mathrm{O}$ abundances are near or below the analytical resolution of the EPMA (Table S1). Experiments with 40-50\% Na loss contain clinopyroxene with $0.4-0.7$ wt $\%$ $\mathrm{Na}_{2} \mathrm{O}$ relative to $1.2 \mathrm{wt} \% \mathrm{Na}_{2} \mathrm{O}$ in clinopyroxene from experiments with no $\mathrm{Na}$ loss (Fig. $\mathrm{S} 1)$. Overall, there appears to be less $\mathrm{Na}_{2} \mathrm{O}$ loss in experiments with large pools of melt, 
indicating that the small degree melts produced in near-solidus experiments that are difficult to analyze and not discernible in EDS maps are likely the sink for the missing $\mathrm{Na}_{2} \mathrm{O}$.

In experiments where analyzable melt pools do exist, another possibility for the $\mathrm{Na}_{2} \mathrm{O}$ discrepancy is some amount of Soret diffusion (Soret, 1879); the experimental capsules have $\sim 10^{\circ} \mathrm{C}$ thermal gradient across them, such that it is possible that $\mathrm{Na}$ could be concentrated in phases at the hotter end (Walker et al., 1982). Thus, sampling bias in EPMA point locations could result in an artificially low $\mathrm{Na}_{2} \mathrm{O}$ abundance for a given experiment. Overall, the effect of $\mathrm{Na}_{2} \mathrm{O}$ loss on the resulting mineral assemblage is presumed to be small for the purposes herein, and the concentration of $\mathrm{Na}_{2} \mathrm{O}$ in clinopyroxene are similar to the average composition of clinopyroxene found in ocean island basalts (OIB) $(\sim 0.72 \mathrm{wt} \%)$ and mid-ocean ridge basalts $(\mathrm{MORB})(\sim 0.61 \mathrm{wt} \%)$ on Earth (Table S1, data from GEOROC http://georoc.mpch-mainz.gwdg.de/georoc/).

\subsection{Description of experimental products}

Experiments for both the HEX1 and HEX2 starting compositions crystallized only olivine, orthopyroxene, clinopyroxene, and spinel, with all four minerals present in all experiments $\leq 1300^{\circ} \mathrm{C}$ (Fig. 2, Table S1). For HEX1 the most abundant mineral is olivine; for HEX2 the dominant mineral is orthopyroxene (Table 2). The subsolidus (melt-free) experimental phase assemblages represent the mineralogy of these hypothetical exoplanets' mantles (Table 2, Table 3, Table S1). 
In the HEX1 experiments, olivine $(2-80 \mu \mathrm{m})$, clinopyroxene $(<1-20 \mu \mathrm{m})$, and spinel are euhedral to anhedral $(<1-10 \mu \mathrm{m})$ while orthopyroxene are subhedral to anhedral (1-40 $\mu \mathrm{m})$ (Fig. 3A, B). Most crystals are equant, but orthopyroxene are sometimes present as needle-like laths that cross-cut clinopyroxene. When present, clinopyroxene and melt tend to be located at the hot end (top) of the charge.

In the HEX2 experiments, olivine $(10-80 \mu \mathrm{m})$ and spinel $(<1-20 \mu \mathrm{m}$, rarely 40 $90 \mu \mathrm{m})$ are euhedral to anhedral while orthopyroxene $(10-50 \mu \mathrm{m})$ and clinopyroxene $(1-$ $50 \mu \mathrm{m}$ ) are subhedral to anhedral (Fig. 3C, D). The majority of the crystals are equant with rare larger phases being tabular. Orthopyroxene are rarely present as equant or tabular chadacrysts inside clinopyroxene. When present, spinel and melt are often preferentially located at the hot end (top) of the charge.

For both starting compositions, experiments run below the solidus have a generally finer-grained texture composed of similarly sized crystals distributed homogenously throughout the charge, with clinopyroxene usually the largest crystal present. Experiments above the solidus are coarser in texture than the subsolidus experiments and crystals sizes are sometimes bimodal.

3.3 Nominally anhydrous exoplanet mantle solidi and melting reactions

The position of the solidus, and therefore the pressure and temperature where melting begins, is dependent on the composition of the material being melted. For example, the Earth's primitive (most unaltered) mantle solidus (Fig. 4) at a given pressure is at a higher temperature than that of altered material such as subducting 
oceanic crust. The temperature and pressure conditions of the solidus for a given mantle composition are important because this translates to the depth in the planet where melting is initiated, the extent of melting likely on a planet with a given thermal profile, and the composition of the resulting melts and crusts.

The solidus was located in the experimental series by comparing the experiment textures, the composition of the phases, and the modal abundance of the phases calculated by mass balance, including melt (Fig. 5). Experiments above the solidus exhibit coarser, sometimes bimodal mineral sizes and more heterogeneous mineral distributions (Fig. 3), as well as changes in the modal\% of phases involved in the melting reactions (Fig. 5).

For HEX1, the location of the nominally anhydrous solidus is the same as Earth's nominally anhydrous peridotite solidus (Hirschmann, 2000) at the resolution of the experimental spacing in pressure and temperature (Fig. 2A). However, for HEX2, the slope and location of the solidus differs from Earth's; the slope of the HEX2 solidus is $\sim 10^{\circ} \mathrm{C} / \mathrm{kbar}$ relative to $\sim 15^{\circ} \mathrm{C} / \mathrm{kbar}$ for Earth with the location of the solidus shifted $\sim 50^{\circ} \mathrm{C}$ colder than that of Earth's undepleted mantle at $20 \mathrm{kbar}$ (Fig. 2B).

Extents of melting above the solidus, or melt productivity $\left(\mathrm{wt} \% \mathrm{melt} /{ }^{\circ} \mathrm{C}, \mathrm{dF} / \mathrm{d} T\right)$, for HEX1 and HEX2 compositions are slightly higher than that of estimates for Earth's undepleted upper mantle. Experiments performed on compositions simulating Earth's anhydrous undepleted upper mantle produce $0.16 \mathrm{wt} \% \mathrm{melt} /{ }^{\circ} \mathrm{C}$ on average at $10 \mathrm{kbar}$, whereas HEX1 produces $\sim 0.18 \pm 0.04 \mathrm{wt} \%$ melt $/{ }^{\circ} \mathrm{C}$ and $\mathrm{HEX} 2$ produces $\sim 0.21 \pm 0.01$ $\mathrm{wt} \%$ melt $/{ }^{\circ} \mathrm{C}$ (where the uncertainty is due to that of the mass balance calculation used to determine F; Fig. 6). The experiments also suggest that, contrary to Earth, for HEX2, 
melt productivity may decrease as pressure increases, with HEX2 15 kbar experiments producing as little as $0.09 \mathrm{wt} \%$ melt $/{ }^{\circ} \mathrm{C}$ (Fig. 6).

The experiments enable a calculation of melting reactions to describe the change in the proportion of exoplanet mantle phases as melt is extracted. Following the procedure of Kinzler (1997), the calculated melting reactions are normalized to 1 unit mass of melt and are presented in Table 4. Over the pressure range investigated, both starting compositions produce peritectic melting reactions with clinopyroxene, orthopyroxene and spinel reacting to form olivine and melt, similar to anhydrous melting of the Earth's mantle (e.g., Kinzler \& Grove, 1992a). In both compositions, orthopyroxene may be consumed at a higher rate than clinopyroxene and spinel, which is different than typical melting reactions of the Earth's mantle that tend to favor consumption of clinopyroxene (Table 4). For both HEX1 and HEX2, increasing the pressure of melting results in an increased proportion of clinopyroxene consumed.

\section{Discussion}

4.1 Melting reactions, melt compositions, and exoplanet mantle solidi

Although any differences between the exoplanet results and MORB are most likely due to the experimental starting compositions rather than the melting process itself, it is worthwhile to note the differences between of the melting process simulated by the HEX1 and HEX2 experiments versus that which produces MORB. HEX1 and HEX2 
manuscript submitted to JGR: Planets Special Issue Exoplanets: The Nexus of Astronomy and Geoscience

melts are the product of batch melting, which differs from fractional (or near-fractional) melting, the process that is thought to produce MORB (e.g., Baker et al., 1995).

However, at the scale of the questions examined here, pooled near-fractional melts like MORB record the average depths of extraction and are broadly comparable to HEX1 and HEX2 batch melts (e.g., Asimow \& Longhi, 2004; Behn \& Grove, 2015; Krein et al., 2020).

The melting reactions for Earth and the hypothetical exoplanets HEX1 and HEX2 are superficially similar - they each involve the same minerals and have the same products and reactants as the lower pressure (i.e., $<13$ kbar) melting reactions for undepleted mantle compositions on Earth (Kinzler \& Grove, 1992a, 1992b) (see Section 3.3 and Table 4). However, the coefficients of these reactions (i.e., the amounts of each phase consumed or produced) are not identical to those of Earth's mantle (Table 4), nor are the compositions of the residual mineral assemblage or mantle-derived partial melts (Table 5, Table S1). Mantle partial melts produced by HEX1 are basalts (46-50 wt\% $\mathrm{SiO}_{2}$ ) and HEX2 melts are basalts to andesites (50-57 wt $\% \mathrm{SiO}_{2}$; Fig. 7A), with broadly similar $\mathrm{MgO}$ and $\mathrm{FeO}^{\text {tot }}$ contents to Earth OIB and MORB and rocky solar system planet melts: Mg\# 50-78 for HEX1 and Mg\# 45-64 for HEX2 $\left(\mathrm{Mg} \#=\mathrm{MgO} /\left(\mathrm{MgO}+\mathrm{FeO}^{\text {tot }}\right)\right.$, Fig. 7B, Table 5).

The hypothetical exoplanet melts are compared to Earth and terrestrial planet magmas in Figure 7. Although the overall trends of the experimental melts are consistent with other nominally anhydrous Earth melts, these representative exoplanetary melts also have absolute $\mathrm{CaO}$ contents $(11-17 \mathrm{wt} \%$, Table $\mathrm{S} 1)$ that are at the higher end or greater than the range of Earth MORB and OIB compositions $(<15 \mathrm{wt} \%)$, as well as 
manuscript submitted to JGR: Planets Special Issue Exoplanets: The Nexus of Astronomy and Geoscience

representative solar system magma compositions ( $<12 \%$; Fig. 7C; Gale et al., 2013; Santos et al., 2015; Squyres et al., 2007; Treiman, 2007; Vander Kaaden et al., 2017) . Compared to the modal mineralogy of a non-depleted bulk Earth mantle composition (Hart \& Zindler, 1986), HEX1 yields about the same amount of the Ca-bearing phase clinopyroxene (16\% for HEX1 versus $15 \%$ for Earth) and spinel (9\% versus $10 \%$ for Earth; Table 3). The mantle mineralogy produced by the HEX1 bulk composition is composed of $8 \%$ less olivine and 7\% more orthopyroxene than Earth's primitive upper mantle (Table 3). When a eutectic melt composition for the HEX1 bulk composition (experiment $\mathrm{R} 85$ : $10 \mathrm{kbar} 1250^{\circ} \mathrm{C}$ ) is plotted on an olivine-clinopyroxene-quartz pseudoternary (Fig. S2), the mantle multiple saturation point-where the melt is in equilibrium with all the mantle minerals - is shifted away from the olivine vertex as compared to the predicted $10 \mathrm{kbar}$ multiple saturation point for a nominally anhydrous Earth MORB. This demarcates the expansion of the olivine primary phase field for $\mathrm{HEX} 1$, as is expected for a bulk composition with $\mathrm{Mg} / \mathrm{Si}$ greater than Earth's undepleted upper mantle (Table 1). HEX1 mineralogy is dominated by olivine, a mineral that incorporates minimal $\mathrm{Ca}$, leaving equilibrium melts $\mathrm{Ca}$-rich at $11-15 \mathrm{wt} \% \mathrm{CaO}$, which is at the high extrema of analogous nominally anhydrous melts of the Earth's upper mantle (e.g., MORB and OIB compositions) and higher than other solar system melts (Fig. 7C). Melts produced in the HEX2 experiments also exhibit a high $\mathrm{CaO}$ content (12-17 $\mathrm{wt} \%$ ). Because of the high $\mathrm{SiO}_{2}$ content and high $\mathrm{Ca} / \mathrm{Al}$ ratio of the starting composition, HEX2 experiments yield 4x more orthopyroxene than clinopyroxene as well as almost 9x less olivine than HEX1 (Table 3). Similar to HEX1, HEX2 yields melts with CaO higher than analogous melts of Earth's mantle as a result of melting reactions favoring the 
manuscript submitted to JGR: Planets Special Issue Exoplanets: The Nexus of Astronomy and Geoscience

consumption of clinopyroxene over orthopyroxene due to their stoichiometry. HEX2's low bulk $\mathrm{Al}_{2} \mathrm{O}_{3}$ content (3.76 wt $\%$, Table 1) relative to that of the non-depleted bulk Earth mantle (4.06 wt\%; Hart \& Zindler, 1986), as well as the abundance of Fe-bearing orthopyroxene, results in a lower phase proportion of spinel in the residual assemblage produced by HEX2 relative to Earth's non-depleted mantle (6\% versus 10\%; Table 3; Hart \& Zindler, 1986).

The differences in the HEX1 and HEX2 solidi (the former of which is indistinguishable from the Earth's undepleted solidus over the pressure-temperature range investigated here) can be elucidated by comparing the bulk experimental starting compositions (Table 1). Increased bulk Mg\# has been shown to increase the temperature of the nominally anhydrous Earth peridotite solidus (Hirschmann, 2000). For the HEX1 bulk composition, $\mathrm{Mg \#}$ is the same as for Earth's undepleted mantle ( 90 ; Table 1; Hart \& Zindler, 1986) and so as expected, HEX1's solidus does not deviate from that of Earth (Fig. 2A). And, in accordance with the demonstrated trend between $\mathrm{Mg} \#$ and solidus temperature (Hirschmann, 2000), HEX2's lower bulk Mg\# ( 87) correctly predicts a lower solidus temperature than that of Earth and HEX1 (see Section 3.3; Fig. 2B, Table 1), resulting in a solidus slope that varies $\sim 5^{\circ} \mathrm{C} / \mathrm{kbar}$ relative to Earth's nominally anhydrous undepleted mantle solidus (Fig. 2B). Workers have used similar experiments to predict the location of mantle solidi for other rocky bodies in our solar system such as Mars, whose nominally anhydrous solidus is estimated to have a slope similar to that of Earth, although possibly shifted $\sim 35^{\circ} \mathrm{C}$ cooler in the upper mantle (Bertka \& Holloway, 1994; Duncan et al., 2018; Matsukage et al., 2013). The implications of this differing 
solidus slope for this potential end member of exoplanet silicate mantles are discussed in the following section.

\subsection{Decompression melting}

The petrological conditions explored herein are relevant for silicate planets with a differentiated core. Decompression melting is the most common mantle melting scenario on these planets (Grove \& Till, 2015) to which these results can be applied. Adiabatic decompression melting occurs when solid mantle rises towards the planet's surface via convection, such that its pressure-temperature profile during ascent is dictated by an adiabat (for Earth: $\sim 1.2^{\circ} \mathrm{C} / \mathrm{kbar}$ or $\sim 0.3^{\circ} \mathrm{C} / \mathrm{km}$; Cammarano et al., 2003; Katsura et al., 2010; Kinzler \& Grove, 1992b). Eventually a rising packet of mantle will intersect the mantle's solidus and begin to melt (Fig. 4, arrow). This process does not require Earthlike plate tectonics and could be caused by an impact (e.g., Jones et al., 2002; Roberts \& Barnouin, 2012) or by unloading of the crust due to ice removal (e.g., Maclennan et al., 2002; Praetorius et al., 2016).

Current models indicate that the adiabatic gradients $(\mathrm{d} T / \mathrm{d} P)$ of rocky exoplanets are most sensitive to interior structure as represented by core-mass fraction (CMF), a ratio indicating what proportion of the bulk planet's Fe resides in the core where it would speciate as metallic Fe instead of as $\mathrm{FeO}$ or $\mathrm{Fe}_{2} \mathrm{O}_{3}$ in the mantle (Unterborn \& Panero, 2019). Therefore a hypothetical exoplanet with the same approximate size and CMF as Earth $(\sim 0.32)$ is predicted to have an adiabatic gradient similar to Earth (Unterborn \& Panero, 2019). Thus, for an exoplanet with an Earth-like mantle potential temperature 
manuscript submitted to JGR: Planets Special Issue Exoplanets: The Nexus of Astronomy and Geoscience

( $\left.T_{p o t}\right)$ of $1330^{\circ} \mathrm{C}$ (Putirka, 2016) and a mantle with a HEX1 bulk composition, adiabatically ascending mantle will intersect this solidus and begin to melt by $\sim 20 \mathrm{kbar}$ (Fig. 4). If we assume the same scenario for a HEX2-composition exoplanet mantle and extrapolate the experimentally-determined solidus to greater pressures, then decompression melting begins at $\sim 90 \mathrm{kbar}$ - much higher pressures than those thought to generate MORB and other common decompression melts in the modern Earth. Although $\mathrm{dF} / \mathrm{d} T$ for a HEX2 starting composition decreases as pressure increases from 10 to 20 kbar, the implied more than 4-fold increase in initial depth of melting for this hypothetical exoplanet could result in a much greater total extent of melting than is produced by modern decompression melting on Earth.

The location of the HEX2 solidus (Fig. 4) implies that exoplanet bulk mantle compositions with higher $\mathrm{Ca} / \mathrm{Al}$ ratios than that of Earth's undepleted mantle will be prone to surficial magma oceans. Assuming an Earth-like adiabat, there is only a narrow range of $T_{p o t}\left(<1330^{\circ} \mathrm{C}\right)$ that would allow decompression melting on such a planet without the entire upper mantle remaining above or below the solidus (Fig. 4). Additionally, $T_{p o t}$ may have been higher $\left(1500-1600^{\circ} \mathrm{C}\right)$ throughout much of Earth's history (Herzberg et al., 2010) and it is reasonable that an exoplanet could have $T_{p o t} \geq$ $1600^{\circ} \mathrm{C}$, thereby increasing the likelihood of an early magma ocean for exoplanets with high $\mathrm{Ca} / \mathrm{Al}$ mantle compositions.

If an exoplanet of HEX2 composition does have a $T_{p o t}$ such that a magma ocean is avoided, it is possible that it may not be volcanically active. After the mantle begins to melt, the liquid must segregate from the solid residuum and ascend, where it may either erupt onto the surface or stall in the crust. This migration of melt depends on many 
manuscript submitted to JGR: Planets Special Issue Exoplanets: The Nexus of Astronomy and Geoscience

factors, but it is possible to employ a simplified scenario in which only the density contrast between the melt and the residuum is used to approximate the relative velocities of each experimental melt as compared to MORB (Daines \& Pec, 2015). Using DensityX (Iacovino \& Till, 2018), a program that calculates the density of anhydrous and hydrous silicate melts based on pressure, temperature, and composition, the anhydrous densities of melt produced by HEX1 and HEX2 at near-solidus conditions were calculated to be 2.92 $\mathrm{g} / \mathrm{cm}^{3}$ and $2.90 \mathrm{~g} / \mathrm{cm}^{3}$, respectively. These calculated melt densities are at the high end of natural Earth nominally anhydrous magma densities (Iacovino \& Till, 2018), due mostly to the higher $\mathrm{FeO}^{\text {tot }}$ content of the exoplanet melts. Residuum densities were determined using the mantle modes (Table 3) and average densities of the appropriate minerals (mindat.org) and found to be $3.35 \mathrm{~g} / \mathrm{cm}^{3}$ for HEX1 and $3.30 \mathrm{~g} / \mathrm{cm}^{3}$ for HEX2. When comparing these densities to the same calculations for average MORB (Gale et al., 2013) and undepleted Earth mantle modes (Hart \& Zindler, 1986), we find that for the same porosity, viscosity, $g$, and melt fraction extracted, HEX1's melt migration velocity could be $\sim 30 \%$ slower than that of Earth MORB and HEX2's melt migration velocity could be $\sim 40 \%$ slower (Daines \& Pec, 2015). This slower migration rate indicates that any partial melts from silicate mantles higher in $\mathrm{Ca} / \mathrm{Al}$ than Earth's mantle could be more likely to stall and crystallize as igneous intrusions, or that generated melt may fail to coalesce into an eruptible melt altogether.

Neither of these scenarios for an exoplanet with a HEX2 mantle composition is favorable for its habitability, at least in the short term. As long as a magma ocean persists, it is unlikely that life as we know it would evolve or persevere unless several conditions are met to ensure the availability of elements necessary for life (a process that, 
on Earth, requires weathering of rock to release phosphorus (Glaser et al., 2020; Hinkel et al., 2020). These conditions may include a volatile abundance high enough to exceed the amount that would be soluble in the mass of magma present; a volume of volatiles on top of the magma ocean large enough to prevent the volatile envelope from boiling away; and atmospheric conditions and an orbital distance appropriate for the stability and retention of a liquid-phase volatile envelope that could interact with the molten rock. Similarly, if a solid-surface exoplanet has no volcanism (as HEX2's melt-mantle density contrast could suggest) it may not have an efficient way to cycle bioessential elements back to the surface to support life. Of course, it is not necessary for a planet to have Earth-like plate tectonics or archetypal stratovolcanoes in order to cycle elements. For example, volatiletriggered melting initiated by a lithospheric gravitational instability (Elkins-Tanton, 2007) may produce melt. However, HEX2's unfavorable melt-mantle density contrast could still prevent these melts from reaching the surface where bioessential elements can be utilized by organisms, which would be an additional challenge to the planet's ability to support life.

\subsection{Implications for volcanic degassing}

At present, knowledge of the specific characteristics of rocky exoplanets is largely limited to their host star composition, amount of stellar irradiance, orbital radius, mass, and planetary radius (atmospheric thickness is included in this measurement). There are methods to detect or infer the presence of an atmosphere (Koll et al., 2019; Kreidberg, 2018; Kreidberg et al., 2019; Mansfield et al., 2019) and spectroscopic characterization of 
manuscript submitted to JGR: Planets Special Issue Exoplanets: The Nexus of Astronomy and Geoscience

exoplanet atmospheres will soon be possible via missions such as NASA's James Webb Space Telescope (JWST), ESA’s Characterising Exoplanet Satellite (CHEOPS), and ESA's Atmospheric Remote-sensing Infrared Exoplanet Large-survey (ARIEL), and ground-based efforts such as the European Extremely Large Telescope's (ELT) Midinfrared ELT Imager and Spectrograph (METIS). Unfortunately, measurements of surface spectra are unlikely to be returned until missions such as NASA's Large UV/Optical/IR Surveyor (LUVOIR), so it behooves the community to experimentally investigate exoplanet melt compositions; the link between melt composition, outgassed volcanic volatiles, and atmosphere composition may allow for the deduction of geochemical properties of the solid interior based on future exoplanet atmospheric data (e.g., Bower et al., 2019; Spaargaren et al., 2020). In this section, Earth-based volatile solubility models are employed to provide a first order approximation of the potential volatile content of the experimentally produced exoplanet melts.

$\mathrm{H}_{2} \mathrm{O}$ and $\mathrm{CO}_{2}$, the $\mathrm{H}$ and $\mathrm{C}$ species dominant at the oxidizing conditions of these experiments, are the two most abundant volcanic volatiles (Giggenbach, W.F., 1996; Wallace et al., 2015). Earth MORBs generally carry $<1 \mathrm{wt} \% \mathrm{H}_{2} \mathrm{O}$ and $<400 \mathrm{ppm} \mathrm{CO}_{2}$ (Wallace et al., 2015). Solubility models based on experimental and natural data show that as $\mathrm{SiO}_{2}$ content increases, $\mathrm{H}_{2} \mathrm{O}$ solubility increases, and as $\mathrm{H}_{2} \mathrm{O}$ and $\mathrm{CaO}$ content increase, $\mathrm{CO}_{2}$ solubility increases but eventually decreases as $\mathrm{H}_{2} \mathrm{O}$ continues to rise (Iacono-Marziano et al., 2012; King \& Holloway, 2002; Moore, 2008; Papale et al., 2006).

Using VESIcal's (Iacovino et al., in review) implementation of MagmaSat (Ghiorso \& Gualda, 2015), modeling was conducted on the average experimental melt 
manuscript submitted to JGR: Planets Special Issue Exoplanets: The Nexus of Astronomy and Geoscience

compositions (Table 5) at $1250^{\circ} \mathrm{C}$ and $10 \mathrm{kbar}$, with a pure $\mathrm{H}_{2} \mathrm{O}$ fluid composition. These parameters predict $\mathrm{HEX} 1$ melts could store $\leq 10.6 \mathrm{wt} \% \mathrm{H}_{2} \mathrm{O}$ and $\mathrm{HEX} 2$ melts could store $\leq 11.4 \mathrm{wt} \% \mathrm{H}_{2} \mathrm{O}$. A second round of modeling was conducted at the same temperature and pressure with fluid that was half $\mathrm{H}_{2} \mathrm{O}$ and half $\mathrm{CO}_{2}$ by mole which, consistent with the above, yielded a higher $\mathrm{CO}_{2}$ content than when modeling with higher relative abundances of $\mathrm{CO}_{2}$. At these conditions, MagmaSat predicts $\leq 0.8 \mathrm{wt} \% \mathrm{CO}_{2}$ in $\mathrm{HEX} 1$ melts and $\leq 0.9 \mathrm{wt} \% \mathrm{CO}_{2}$ in $\mathrm{HEX} 2$ melts. These results are consistent with the higher $\mathrm{SiO}_{2}$ and $\mathrm{CaO}$ contents of the experimental melts as compared to MORB. Consequently, for exoplanets with silicate mantle compositions similar to HEX1 and HEX2, volatilebearing magmas would likely degas large quantities of $\mathrm{H}_{2} \mathrm{O}$ and $\mathrm{CO}_{2}$ to the atmosphere. Unfortunately, although $\mathrm{H}_{2} \mathrm{O}$ and $\mathrm{CO}_{2}$ may be measured via telescopic spectrometry, at present there is not a method to confirm a specifically volcanic origin for these volatiles.

Sulfur (S) compounds, however, are more distinctly volcanic in origin than $\mathrm{H}_{2} \mathrm{O}$ or $\mathrm{CO}_{2}$, and it has been determined that JWST, for example, could detect atmospheric $\mathrm{SO}_{2}$ if allowed sufficient transits to achieve a favorable signal-to-noise ratio (LustigYaeger et al., 2019). $\mathrm{SO}_{2}$ is a promising candidate for detecting volcanic activity in exoplanet atmospheres because eruptions that are sufficiently explosive could inject $\mathrm{SO}_{2}$ into the stratosphere, a region of the atmosphere where weather does not eliminate the compound, and where it is less vulnerable to photolysis than another common S compound, $\mathrm{H}_{2} \mathrm{~S}$ (Robock, 2000).

Because S was not included in the HEX1 or HEX2 starting compositions, relative solubility is estimated based on $f \mathrm{O}_{2}$ and $\mathrm{FeO}^{\text {tot }}$ content. The solubility of S in Earth's basaltic melts has been the subject of much study (e.g., Holzheid \& Grove, 2002; 
manuscript submitted to JGR: Planets Special Issue Exoplanets: The Nexus of Astronomy and Geoscience

Keppler, 1999; Oppenheimer et al., 2011; Webster et al., 2014; Wykes et al., 2015). At $\mathrm{FMQ}+1$, basaltic melts are estimated to contain only $\sim 0.31$ mole fraction equivalent of sulfate $\left(\mathrm{S}^{6+}\right.$; Jugo et al., 2005) and so the $\mathrm{S}$ budgets of the HEX1 and HEX2 melts are considered to be dominated by sulfide $\left(\mathrm{S}^{2-}\right)$. Above $\sim 5 \mathrm{wt} \% \mathrm{FeO}$, as the $\mathrm{FeO}$ content of a melt increases so does the amount of $\mathrm{S}$ that can be carried in that melt, regardless of water content (O’Neill \& Mavrogenes, 2002; Wykes et al., 2015). The FeO ${ }^{\text {tot }}$ content of HEX1 and HEX2 melts (9-15 wt\%) is comparable to that of Earth OIB (7-16 wt\%) and MORB (7-15 wt\%) and in a simple extrapolation, primary melts of hypothetical exoplanet mantles with bulk compositions and an $\mathrm{fO}_{2}$ similar to those investigated here may be expected to dissolve approximately the same amount of S as Earth melts: $\sim 1500$ 2000 ppm at S- saturation (Jugo et al., 2010; O’Neill \& Mavrogenes, 2002). The Sun plots at a molar Fe/ $\mathrm{Si}=0.85$ (Fig. 1), which is at the midrange of known FGK-type stars (most contain molar $\mathrm{Fe} / \mathrm{Si}=0.3-1.7$; Hinkel et al., 2014). This indicates that $\mathrm{S}$ carrying capacity is likely to vary significantly in primary exoplanetary magmas depending on the $\mathrm{Fe} / \mathrm{Si}$ and $\mathrm{fO}_{2}$ of the exoplanet's bulk mantle.

It is important to note that in addition to the total abundance of volatiles on a given rocky exoplanet, the solubility of volatiles in exoplanet magma directly influences their likelihood of observation in a planetary atmosphere. This is because the amount of volatiles dissolved in magma affects parameters such as viscosity and density, that in turn influence the explosivity of eruptions produced by a volcanic system (Hess \& Dingwell, 1996; Ochs \& Lange, 1999). Depending on a volcanic eruption's explosivity and its latitudinal location relative to atmospheric patterns (i.e., below a region of upwelling), the more likely it is that volcanic gases could be injected into the stratosphere where they 
manuscript submitted to JGR: Planets Special Issue Exoplanets: The Nexus of Astronomy and Geoscience

may persist long enough to be measured by JWST, ARIEL, and ELT (McCormick et al., 1995; Robock, 2000).

4.4 Looking ahead: new exoplanet models and experiments

Most, if not all, existing geochemical models depend on the melting reactions, mineral assemblages, and other trends that are based on a petrological understanding of Earth's interior. Using several available petrologic models (Behn \& Grove, 2015; Ghiorso et al., 2002; Ghiorso \& Sack, 1995; Gualda et al., 2012; Krein et al., 2020; Stixrude \& Lithgow-Bertelloni, 2005), an attempt was made to replicate the melt compositions and phase assemblages produced by the experiments presented in this work. All failed to yield comparable or realistic results (e.g., major phases were omitted, liquidi were calculated at subsolidus temperatures, or models did not converge on a solution). It is apparent that existing models are poorly suited to investigating magma genesis on rocky exoplanets, unless they have a composition essentially identical to that of Earth. There is a clear need for new or updated geochemical models for petrologic applications, as well as for the solubility of volatiles in exoplanetary melts that are dissimilar from melts produced in Earth.

A substantial effort to conduct exoplanetary petrologic experiments like those presented here, as well as to create new models calibrated on these experiments, is needed to assess the chemical composition of exoplanet crusts, magmas, and degassing behavior in order to eventually evaluate their potential to support life. There is a vast composition space yet to be explored as indicated by the breadth of compositions of 
known stars (Fig. 1). In addition to determining melt compositions and volatile solubilities, the improved ability to calculate equations of state for the higher pressures and temperatures of super-Earths is needed to avoid extrapolation of these equations far beyond their empirical foundation (Unterborn \& Panero, 2019). To calibrate new models, it is not practical to conduct experiments on every potential exoplanet in the habitable zone. Thus, using the refractory composition of stars (Fig. 1) to target experiments as is done in this study is recommended, with a particular focus on examining exoplanet compositions that occupy regions of composition space that have not been studied due to their dissimilarity to the compositions of rocky planets in our solar system.

Using future atmospheric spectra and volatile solubility data, it may be possible to make inferences about the bulk silicate exoplanets capable of exhibiting certain atmospheric compositions. Workers are already constructing models and striving to optimize instrumental and observing modes to interpret these future data (Batalha et al., 2018; Greene et al., 2016; Kaltenegger \& Sasselov, 2010; Lustig-Yaeger et al., 2019; Taylor et al., 2020). Although it may be decades before sufficient exoplanet models and observations exist to test these results, it is critical to prepare for these future opportunities by creating the solid planet petrologic and geochemical data needed to facilitate exoplanetary investigations.

\section{Conclusions}

Piston-cylinder partial melting experiments were conducted on two hypothetical bulk silicate exoplanet compositions to compare their petrological characteristics to those 
manuscript submitted to JGR: Planets Special Issue Exoplanets: The Nexus of Astronomy and Geoscience

of Earth's nominally anhydrous undepleted mantle. Experimentally produced melts were compared to Earth melts and magmas from other solar system rocky planets, and also were used to make basic inferences about the potential habitability of exoplanets with similar bulk silicate compositions. Experiments indicate that increasing the $\mathrm{Mg} / \mathrm{Si}$ ratio of the bulk silicate composition of an exoplanet (HEX1) by a modest amount as was done here does not yield substantial changes to the solidus, melting reactions, mantle mineral assemblage, or geochemical characteristics as compared to those of the Earth's undepleted mantle. However, the equilibrium partial mantle melting experiments presented here indicate that increasing the bulk $\mathrm{Ca} / \mathrm{Al}$ ratio and decreasing the $\mathrm{Mg} / \mathrm{Si}$ of an exoplanet's mantle (HEX2) relative to that of Earth's undepleted mantle can result in an initial pressure of melting that is more than $4 \mathrm{x}$ greater, making magma oceans more likely for such mantles, especially in scenarios where the mantle potential temperature is similar to or greater than that on modern Earth. The melt and residuum compositions produced in the experiments point to the possibility that low-degree partial melts of a solid HEX2 mantle may also be less likely to erupt on the exoplanet's surface. Based on these simplified scenarios, exoplanets with bulk silicate compositions similar to HEX2 may be unlikely to host life early in their history and/or as they evolve depending on the presence of effective crust — and thus element_recycling mechanisms.

Both hypothetical exoplanet mantles have Earth mantle-like $\mathrm{FeO}^{\text {tot }}$ contents which suggest their primary melts will have similar S contents to primary magmas on Earth, whereas the analog exoplanetary melt compositions' $\mathrm{CaO}$ and $\mathrm{SiO}_{2}$ contents suggest they may store up to $\sim 20 \mathrm{x}$ more $\mathrm{CO}_{2}$ and $\sim 10 \mathrm{x}$ more $\mathrm{H}_{2} \mathrm{O}$ than is observed for MORB on Earth. Although HEX1 and HEX2 composition exoplanets are not expected to have 
increased $\mathrm{S}$ solubility, their potentially high $\mathrm{H}_{2} \mathrm{O}$ and $\mathrm{CO}_{2}$ contents could increase the explosivity of volcanic eruptions, releasing more of these compounds into the atmosphere, as well as propelling them to regions of the atmosphere that would make a telescopic observation more favorable.

An experimental determination of rocky exoplanet mantle mineralogy and mantle-derived melt compositions is the foundation for understanding the geochemical relationships between the subsurface, surface, and atmosphere of these chemically foreign bodies. This work represents an early step towards a future when the discipline of exoplanet science is not compositionally limited to extrapolation from experiments and models that are based on Earth-like compositions. 


\section{Acknowledgements}

New data produced by these experiments are available in the Supplement, as well as at AstroRepo (https://doi.org/10.26022/IEDA/111913). Thank you to associate editor Ananya Mallik and to Chris Renggli and two anonymous reviewers whose feedback and insightful questions helped to enrich this manuscript. Thanks to Axel Wittmann, Chelsea Allison, Stephanie Brown, Steve Desch, Sierra Ferguson, Crystylynda Fudge, Chris Haberle, Rick Hervig, Natalie Hinkel, Kayla Iacovino, Aleisha Johnson, Thad Komacek, Heather Meyer, Kurt Roggensack, Everett Shock, Cayman Unterborn, Jax Webb, and the EPIC group at ASU. The results reported herein benefited from collaborations and/or information exchange within NASA's Nexus for Exoplanet System Science (NExSS) research coordination network sponsored by NASA's Science Mission Directorate. The research shown here acknowledges use of the Hypatia Catalog Database, an online compilation of stellar abundance data as described in Hinkel et al. (2014, AJ, 148, 54), which was supported by NExSS and the Vanderbilt Initiative in Data-Intensive Astrophysics (VIDA). This work was supported by the U.S. National Science Foundation under Graduate Research Fellowship no. 026257-001 to K.K.B., an ASU Graduate College Completion Fellowship to K.K.B, an ASU College of Liberal Arts and Sciences Undergraduate Summer Research Fellowship to M.G.P., and the ASU-NExSS grant (NNX15AD53G to Steve Desch). The EPMA facilities at ASU are in part supported by the National Nanotechnology Coordinated Infrastructure grant ECCS-1542160. 
manuscript submitted to JGR: Planets Special Issue Exoplanets: The Nexus of Astronomy and Geoscience

\section{References}

Asimow, P. D., \& Longhi, J. (2004). The Significance of Multiple Saturation Points in the Context of Polybaric Near-fractional Melting. Journal of Petrology, 45(12), 2349-2367. https://doi.org/10.1093/petrology/egh043

Asplund, M., Grevesse, N., \& Sauval, A. J. (2005). The Solar Chemical Composition. In T. G. Barnes \& F. N. Bash (Eds.), Cosmic abundances as records of stellar evolution and nucleosynthesis (Vol. 336, pp. 25-38). San Francisco, CA, USA.

Baker, M. B., \& Stolper, E. M. (1994). Determining the composition of high-pressure mantle melts using diamond aggregates. Geochimica et Cosmochimica Acta, 58(13), 2811-2827. https://doi.org/10.1016/0016-7037(94)90116-3

Baker, M. B., Hirschmann, M. M., \& Ghiorsot, M. S. (1995). Compositions of nearsolidus peridotite melts from experiments and thermodynamic calculations. Nature, 375, 308-311. https://doi.org/doi.org/10.1038/375308a0

Batalha, N. E., Lewis, N. K., Line, M. R., Valenti, J., \& Stevenson, K. (2018). Strategies for Constraining the Atmospheres of Temperate Terrestrial Planets with JWST. The Astrophysical Journal, 856(2), L34. https://doi.org/10.3847/2041$8213 / \mathrm{aab} 896$

Behn, M. D., \& Grove, T. L. (2015). Melting systematics in mid-ocean ridge basalts: Application of a plagioclase-spinel melting model to global variations in major element chemistry and crustal thickness: MID-OCEAN RIDGE MELTING SYSTEMATICS. Journal of Geophysical Research: Solid Earth, 120(7), 48634886. https://doi.org/10.1002/2015JB011885 
manuscript submitted to JGR: Planets Special Issue Exoplanets: The Nexus of Astronomy and Geoscience

Bertka, C. M., \& Holloway, J. R. (1994). Anhydrous partial melting of an iron-rich mantle I: subsolidus phase assemblages and partial melting phase relations at 10 to 30 kbar. Contributions to Mineralogy and Petrology, 115, 313-322. https://doi.org/10.1007/BF00310770

Bond, J. C., O’Brien, D. P., \& Lauretta, D. S. (2010). The Compositional Diversity of Extrasolar Terrestrial Planets I. In Situ Simulations. The Astrophysical Journal, 715(2), 1050-1070. https://doi.org/10.1088/0004-637X/715/2/1050

Bower, D. J., Kitzmann, D., Wolf, A. S., Sanan, P., Dorn, C., \& Oza, A. V. (2019). Linking the evolution of terrestrial interiors and an early outgassed atmosphere to astrophysical observations. Astronomy \& Astrophysics, 631, A103. https://doi.org/10.1051/0004-6361/201935710

Boyd, F. R., \& England, J. L. (1960). Apparatus for Phase-Equilibrium Measurements at Pressures up to 50 Kilobars and Temperatures up to $1750^{\circ} \mathrm{C}$. Journal of Geophysical Research, 65(2), 741-748.

Brugman, K. K., Phillips, M. G., \& Till, C. B. (2021). Experimental Determination of Mantle Solidi and Melt Compositions for Two Likely Rocky Exoplanet Compositions, Version 1.0. Interdisciplinary Earth Data Alliance (IEDA). https://doi.org/10.26022/IEDA/111913

Bryson, S., Kunimoto, M., Kopparapu, R. K., Coughlin, J. L., Borucki, W. J., Koch, D., et al. (2020). The Occurrence of Rocky Habitable-zone Planets around Solar-like Stars from Kepler Data. The Astronomical Journal, 161(1), 32. https://doi.org/10.3847/1538-3881/abc418 
manuscript submitted to JGR: Planets Special Issue Exoplanets: The Nexus of Astronomy and Geoscience

Byrne, P. K. (2019). A comparison of inner Solar System volcanism. Nature Astronomy, 4, 321-327. https://doi.org/10.1038/s41550-019-0944-3

Cammarano, F., Goes, S., Vacher, P., \& Giardini, D. (2003). Inferring upper-mantle temperatures from seismic velocities. Physics of the Earth and Planetary Interiors, 138(3-4), 197-222. https://doi.org/10.1016/S0031-9201(03)00156-0

Carter-Bond, J. C., O’Brien, D. P., Delgado Mena, E., Israelian, G., Santos, N. C., \& González Hernández, J. I. (2012). Low Mg/Si Planetary Host Stars and Their Mgdepleted Terrestrial Planets. The Astrophysical Journal, 747(L2), 6. https://doi.org/10.1088/2041-8205/747/1/L2

Daines, M. J., \& Pec, M. (2015). Migration of Melt. In The Encyclopedia of Volcanoes (2nd ed.). Amsterdam; Boston: Elsevier/AP.

Daviau, K., Meng, Y., \& Lee, K. K. M. (2019). SiO 2 -SiC Mixtures at High Pressures and Temperatures: Implications for Planetary Bodies Containing SiC. Journal of Geophysical Research: Planets, 124(8), 2294-2305.

https://doi.org/10.1029/2018JE005856

Dorn, C., Noack, L., \& Rozel, A. B. (2018). Outgassing on stagnant-lid super-Earths. Astronomy \& Astrophysics, 614, A18. https://doi.org/10.1051/0004$6361 / 201731513$

Duffy, T. S., \& Smith, R. F. (2019). Ultra-High Pressure Dynamic Compression of Geological Materials. Frontiers in Earth Science, 7, 23. https://doi.org/10.3389/feart.2019.00023 
manuscript submitted to JGR: Planets Special Issue Exoplanets: The Nexus of Astronomy and Geoscience

Duncan, M. S., Schmerr, N. C., Bertka, C. M., \& Fei, Y. (2018). Extending the Solidus for a Model Iron-Rich Martian Mantle Composition to $25 \mathrm{GPa}$. Geophysical Research Letters, 45(19), 10,211-10,220. https://doi.org/10.1029/2018GL078182

Elkins-Tanton, L. T. (2007). Continental magmatism, volatile recycling, and a heterogeneous mantle caused by lithospheric gravitational instabilities. Journal of Geophysical Research, 112(B3). https://doi.org/10.1029/2005JB004072

Falloon, T. J., Green, D. H., Danyushevsky, L. V., \& Faul, U. H. (1999). Peridotite Melting at 1.0 and 1.5 GPa: an Experimental Evaluation of Techniques using Diamond Aggregates and Mineral Mixes for Determination of Near-solidus Melts, 40(9), 33. https://doi.org/10.1093/petrology/42.12.2363

Feldman, U. (1992). Elemental abundances in the upper solar atmosphere. Physica Scripta, 46(3), 202-220. https://doi.org/10.1088/0031-8949/46/3/002

Filiberto, J. (2014). Magmatic diversity on Venus: Constraints from terrestrial analog crystallization experiments. Icarus, 231, 131-136. https://doi.org/10.1016/j.icarus.2013.12.003

Fulton, B. J., Petigura, E. A., Howard, A. W., Isaacson, H., Marcy, G. W., Cargile, P. A., et al. (2017). The California-Kepler Survey. III. A Gap in the Radius Distribution of Small Planets. The Astronomical Journal, 154(3), 109. https://doi.org/10.3847/1538-3881/aa80eb

Gale, A., Dalton, C. A., Langmuir, C. H., Su, Y., \& Schilling, J.-G. (2013). The mean composition of ocean ridge basalts: MEAN MORB. Geochemistry, Geophysics, Geosystems, 14(3), 489-518. https://doi.org/10.1029/2012GC004334 
manuscript submitted to JGR: Planets Special Issue Exoplanets: The Nexus of Astronomy and Geoscience

Ghiorso, M. S., \& Gualda, G. A. R. (2015). An H2O-CO2 mixed fluid saturation model compatible with rhyolite-MELTS. Contributions to Mineralogy and Petrology, 169(6). https://doi.org/10.1007/s00410-015-1141-8

Ghiorso, M. S., \& Sack, R. O. (1995). Chemical mass transfer in magmatic processes IV. A revised and internally consistent thermodynamic model for the interpolation and extrapolation of liquid-solid equilibria in magmatic systems at elevated temperatures and pressures. Contributions to Mineralogy and Petrology, 119, $197-212$.

Ghiorso, M. S., Hirschmann, M. M., Reiners, P. W., \& Kress, V. C. (2002). The pMELTS: A revision of MELTS for improved calculation of phase relations and major element partitioning related to partial melting of the mantle to $3 \mathrm{GPa}$ : pMELTS, A REVISION OF MELTS. Geochemistry, Geophysics, Geosystems, 3(5), 1-35. https://doi.org/10.1029/2001GC000217

Giggenbach, W.F. (1996). Chemical Composition of Volcanic Gases. In Monitoring and Mitigation of Volcano Hazards (pp. 221-256). Berlin, Heidelberg: Springer. Retrieved from 10.1007/978-3-642-80087-0_7

Glaser, D. M., Hartnett, H. E., Desch, S. J., Unterborn, C. T., Anbar, A., Buessecker, S., et al. (2020). Detectability of Life Using Oxygen on Pelagic Planets and Water Worlds. The Astrophysical Journal, 893(2), 163. https://doi.org/10.3847/1538$4357 / \mathrm{ab} 822 \mathrm{~d}$

Greene, T. P., Line, M. R., Montero, C., Fortney, J. J., Lustig-Yaeger, J., \& Luther, K. (2016). Characterizing Transiting Exoplanet Atmospheres with JWST. The Astrophysical Journal, 817(1), 17. https://doi.org/10.3847/0004-637X/817/1/17 
manuscript submitted to JGR: Planets Special Issue Exoplanets: The Nexus of Astronomy and Geoscience

Grove, T. L., \& Krawczynski, M. J. (2009). Lunar Mare Volcanism: Where Did the Magmas Come From? Elements, 5(1), 29-34. https://doi.org/10.2113/gselements.5.1.29

Grove, Timothy L., \& Till, C. B. (2015). Melting the Earth’s Upper Mantle. In H. Sigurdsson, B. Houghton, S. McNutt, H. Rymer, \& J. Stix (Eds.), The Encyclopedia of Volcanos (2nd ed.). Amsterdam, Boston: Elsevier/AP.

Gualda, G. A. R., Ghiorso, M. S., Lemons, R. V., \& Carley, T. L. (2012). RhyoliteMELTS: a Modified Calibration of MELTS Optimized for Silica-rich, Fluidbearing Magmatic Systems. Journal of Petrology, 53(5), 875-890. https://doi.org/10.1093/petrology/egr080

Hakim, K., van Westrenen, W., \& Dominik, C. (2018). Capturing the oxidation of silicon carbide in rocky exoplanetary interiors. Astronomy \& Astrophysics, 618(L6), 5. https://doi.org/10.1051/0004-6361/201833942

Hakim, K., Spaargaren, R., Grewal, D. S., Rohrbach, A., Berndt, J., Dominik, C., \& van Westrenen, W. (2019). Mineralogy, Structure, and Habitability of CarbonEnriched Rocky Exoplanets: A Laboratory Approach. Astrobiology, 19(7), 867884. https://doi.org/10.1089/ast.2018.1930

Hart, S. R., \& Zindler, A. (1986). In Search of a Bulk-Earth Composition. Chemical Geology, 57, 247-267. https://doi.org/10.1016/0009-2541(86)90053-7

Hays, J. F. (1966). Lime-Alumina-Silica, 234-239.

Herzberg, C., Condie, K., \& Korenaga, J. (2010). Thermal history of the Earth and its petrological expression. Earth and Planetary Science Letters, 292(1-2), 79-88. https://doi.org/10.1016/j.epsl.2010.01.022 
manuscript submitted to JGR: Planets Special Issue Exoplanets: The Nexus of Astronomy and Geoscience

Hess, K.-U., \& Dingwell, D. D. (1996). Viscosities of hydrous leucogranitic melts: A non-Arrhenian model. American Mineralogist, 81, 1297-1300. https://doi.org/10.2138/am-1996-9-1031

Hinkel, N. R., \& Unterborn, C. T. (2018). The Star-Planet Connection. I. Using Stellar Composition to Observationally Constrain Planetary Mineralogy for the 10 Closest Stars. The Astrophysical Journal, 853(83), 14. https://doi.org/10.3847/1538-4357/aaa5b4

Hinkel, N. R., Timmes, F. X., Young, P. A., Pagano, M. D., \& Turnbull, M. C. (2014). Stellar Abundances in the Solar Neighborhood: The Hypatia Catalog. The Astronomical Journal, 148(54), 33. https://doi.org/10.1088/0004-6256/148/3/54

Hinkel, N. R., Young, P. A., Pagano, M. D., Desch, S. J., Anbar, A. D., Adibekyan, V., et al. (2016). A comparison of stellar elemental abundance techniques and measurements. The Astrophysical Journal Supplement Series, 226(1), 4. https://doi.org/10.3847/0067-0049/226/1/4

Hinkel, N. R., Hartnett, H. E., \& Young, P. A. (2020). The Influence of Stellar Phosphorus on Our Understanding of Exoplanets and Astrobiology. The Astrophysical Journal, 900(2), L38. https://doi.org/10.3847/2041-8213/abb3cb

Hirschmann, M. M. (2000). Mantle solidus: Experimental constraints and the effects of peridotite composition. Geochemistry, Geophysics, Geosystems, 1(10), 26. https://doi.org/10.1029/2000GC000070

Holzheid, A., \& Grove, T. L. (2002). Sulfur saturation limits in silicate melts and their implications for core formation scenarios for terrestrial planets. American Mineralogist, 87(2-3), 227-237. https://doi.org/10.2138/am-2002-2-304 
manuscript submitted to JGR: Planets Special Issue Exoplanets: The Nexus of Astronomy and Geoscience

Hu, R., Seager, S., \& Bains, W. (2012). Photochemistry in Terrestrial Exoplanet Atmospheres. I. Photochemistry Model and Benchmark Cases. The Astrophysical Journal, 761(2), 166. https://doi.org/10.1088/0004-637X/761/2/166

Iacono-Marziano, G., Morizet, Y., Le Trong, E., \& Gaillard, F. (2012). New experimental data and semi-empirical parameterization of $\mathrm{H} 2 \mathrm{O}-\mathrm{CO} 2$ solubility in mafic melts. Geochimica et Cosmochimica Acta, 97, 1-23. https://doi.org/10.1016/j.gca.2012.08.035

Iacovino, K., \& Till, C. (2018). DensityX: A program for calculating the densities of hydrous magmatic liquids from $427-1,627^{\circ} \mathrm{C}$ and up to $30 \mathrm{kbar}$. Volcanica, 2(1), 1-10. https://doi.org/10.30909/vol.02.01.0110

Iacovino, K., Guild, M. R., \& Till, C. B. (2020). Aqueous fluids are effective oxidizing agents of the mantle in subduction zones. Contributions to Mineralogy and Petrology, 175(4). https://doi.org/10.1007/s00410-020-1673-4

Iacovino, K., Matthews, S., Wieser, P., Moore, G., \& Bégué, F. (in review). VESIcal Part I: An open-source thermodynamic model engine for mixed volatile (H2O-CO2) solubility in silicate melts. https://doi.org/10.31223/X5D606

Jofré, P., Heiter, U., Soubiran, C., Blanco-Cuaresma, S., Masseron, T., Nordlander, T., et al. (2015). Gaia FGK benchmark stars: abundances of $\alpha$ and iron-peak elements. Astronomy \& Astrophysics, 582, 49. https://doi.org/10.1051/0004$6361 / 201526604$

Johnson, J. A., Petigura, E. A., Fulton, B. J., Marcy, G. W., Howard, A. W., Isaacson, H., et al. (2017). The California-Kepler Survey. II. Precise Physical Properties of 
manuscript submitted to JGR: Planets Special Issue Exoplanets: The Nexus of Astronomy and Geoscience

2025 Kepler Planets and Their Host Stars. The Astronomical Journal, 154(3), 108. https://doi.org/10.3847/1538-3881/aa80e7

Jones, A. P., Price, G. D., Price, N. J., DeCarli, P. S., \& Clegg, R. A. (2002). Impact induced melting and the development of large igneous provinces. Earth and Planetary Science Letters, 202(3-4), 551-561. https://doi.org/10.1016/S0012$821 X(02) 00824-5$

Jugo, P. J., Luth, R. W., \& Richards, J. P. (2005). Experimental data on the speciation of sulfur as a function of oxygen fugacity in basaltic melts. Geochimica et Cosmochimica Acta, 69(2), 497-503. https://doi.org/10.1016/j.gca.2004.07.011

Jugo, P. J., Wilke, M., \& Botcharnikov, R. E. (2010). Sulfur K-edge XANES analysis of natural and synthetic basaltic glasses: Implications for S speciation and $\mathrm{S}$ content as function of oxygen fugacity. Geochimica et Cosmochimica Acta, 74(20), 59265938. https://doi.org/10.1016/j.gca.2010.07.022

Kaltenegger, L., \& Sasselov, D. (2010). Detecting planetary geochemical cycles on exoplanets: Atmospheric signatures and the case of SO2. The Astrophysical Journal, 708(2), 1162-1167. https://doi.org/10.1088/0004-637X/708/2/1162

Kane, S. R., Hill, M. L., Kasting, J. F., Kopparapu, R. K., Quintana, E. V., Barclay, T., et al. (2016). A Catalog of Kepler Habitable Zone Exoplanet Candidates. The Astrophysical Journal, 830(1), 1. https://doi.org/10.3847/0004-637X/830/1/1

Kasting, J. F., Whitmire, D. P., \& Reynolds, R. T. (1993). Habitable Zones around Main Sequence Stars. Icarus, 101(1), 108-128. https://doi.org/10.1006/icar.1993.1010 
manuscript submitted to JGR: Planets Special Issue Exoplanets: The Nexus of Astronomy and Geoscience

Katsura, T., Yoneda, A., Yamazaki, D., Yoshino, T., \& Ito, E. (2010). Adiabatic temperature profile in the mantle. Physics of the Earth and Planetary Interiors, 183(1-2), 212-218. https://doi.org/10.1016/j.pepi.2010.07.001

Keppler, H. (1999). Experimental Evidence for the Source of Excess Sulfur in Explosive Volcanic Eruptions. Science, 284(5420), 1652-1654.

https://doi.org/10.1126/science.284.5420.1652

Kiefer, W. S., Filiberto, J., Sandu, C., \& Li, Q. (2015). The effects of mantle composition on the peridotite solidus: Implications for the magmatic history of Mars. Geochimica et Cosmochimica Acta, 162, 247-258. https://doi.org/10.1016/j.gca.2015.02.010

King, P. L., \& Holloway, J. R. (2002). CO2 solubility and speciation in intermediate (andesitic) melts: the role of $\mathrm{H} 2 \mathrm{O}$ and composition. Geochimica et Cosmochimica Acta, 66(9), 1627-1640. https://doi.org/10.1016/S0016-7037(01)00872-9

Kinzler, R. J. (1997). Melting of mantle peridotite at pressures approaching the spinel to garnet transition: Application to mid-ocean ridge basalt petrogenesis. Journal of Geophysical Research: Solid Earth, 102(B1), 853-874.

https://doi.org/10.1029/96JB00988

Kinzler, R. J., \& Grove, T. L. (1992a). Primary magmas of mid-ocean ridge basalts 1. Experiments and methods. Journal of Geophysical Research, 97(B5), 6885. https://doi.org/10.1029/91JB02840

Kinzler, R. J., \& Grove, T. L. (1992b). Primary magmas of mid-ocean ridge basalts 2. Applications. Journal of Geophysical Research, 97(B5), 6907. https://doi.org/10.1029/91JB02841 
manuscript submitted to JGR: Planets Special Issue Exoplanets: The Nexus of Astronomy and Geoscience

Kite, E. S., Fegley Jr., B., Schaefer, L., \& Ford, E. B. (2020). Atmosphere Origins for Exoplanet Sub-Neptunes. The Astrophysical Journal, 891(2), 111. https://doi.org/10.3847/1538-4357/ab6ffb

Koll, D. D. B., Malik, M., Mansfield, M., Kempton, E. M.-R., Kite, E., Abbot, D., \& Bean, J. L. (2019). Identifying Candidate Atmospheres on Rocky M dwarf Planets via Eclipse Photometry. The Astrophysical Journal, 886(140), 13. https://doi.org/10.3847/1538-4357/ab4c91

Kopparapu, R. K., Ramirez, R. M., SchottelKotte, J., Kasting, J. F., Domagal-Goldman, S., \& Eymet, V. (2014). Habitable zones around main-sequence stars: dependence on planetary mass. The Astrophysical Journal, 787(2), L29. https://doi.org/10.1088/2041-8205/787/2/L29

Krawczynski, M. J., \& Grove, T. L. (2012). Experimental investigation of the influence of oxygen fugacity on the source depths for high titanium lunar ultramafic magmas. Geochimica et Cosmochimica Acta, 79, 1-19. https://doi.org/10.1016/j.gca.2011.10.043

Kreidberg, L. (2018). Exoplanet Atmosphere Measurements from Transmission Spectroscopy and Other Planet Star Combined Light Observations. In H. Deeg \& J. Belmonte (Eds.), Handbook of Exoplanets (pp. 1-23). Springer, Cham. Retrieved from 10.1007/978-3-319-30648-3_100-1

Kreidberg, L., Koll, D. D. B., Morley, C., Hu, R., Schaefer, L., Deming, D., et al. (2019). Absence of a thick atmosphere on the terrestrial exoplanet LHS 3844b. Nature, 573(7772), 87-90. https://doi.org/10.1038/s41586-019-1497-4 
manuscript submitted to JGR: Planets Special Issue Exoplanets: The Nexus of Astronomy and Geoscience

Krein, S. B., Behn, M. D., \& Grove, T. L. (2020). Origins of Major Element, Trace Element, and Isotope Garnet Signatures in Mid-Ocean Ridge Basalts. Journal of Geophysical Research: Solid Earth, 125(12).

https://doi.org/10.1029/2020JB019612

Kress, V. C., \& Carmichael, I. S. (1991). The Compressibility of silicate liquids contatining Fe2O3 and the effect of composition, temperature, oxygen fugacity and pressure on their redox states. Contributions to Mineralogy and Petrology, 108, 82-92. https://doi.org/doi.org/10.1007/BF00307328

Lodders, K., Palme, H., \& Gail, H.-P. (2009). 4.4 Abundances of the elements in the Solar System. In J. E. Trümper (Ed.), The Solar System (Vol. 4B). Berlin Heidelberg: Springer-Verlag. Retrieved from 10.1007/978-3-540-88055-4_34

Longhi, J. (2005). Temporal stability and pressure calibration of barium carbonate and talc/pyrex pressure media in a piston-cylinder apparatus. American Mineralogist, 90(1), 206-218. https://doi.org/10.2138/am.2005.1348

Lustig-Yaeger, J., Meadows, V. S., \& Lincowski, A. P. (2019). The Detectability and Characterization of the TRAPPIST-1 Exoplanet Atmospheres with JWST. The Astronomical Journal, 158(1), 27. https://doi.org/10.3847/1538-3881/ab21e0

Maclennan, J., Jull, M., McKenzie, D., Slater, L., \& Grönwald, K. (2002). The link between volcanism and deglaciation in Iceland. Geochemistry, Geophysics, Geosystems, 3(11), 25. https://doi.org/10.1029/2001GC000282

Mansfield, M., Kite, E. S., Hu, R., Koll, D. D. B., Malik, M., Bean, J. L., \& Kempton, E. M.-R. (2019). Identifying Atmospheres on Rocky Exoplanets Through Inferred 
manuscript submitted to JGR: Planets Special Issue Exoplanets: The Nexus of Astronomy and Geoscience

High Albedo. The Astrophysical Journal, 886(141), 11.

https://doi.org/10.3847/1538-4357/ab4c90

Martinez, C. F., Cunha, K., Ghezzi, L., \& Smith, V. V. (2019). A Spectroscopic Analysis of the California-Kepler Survey Sample. I. Stellar Parameters, Planetary Radii, and a Slope in the Radius Gap. The Astrophysical Journal, 875(1), 29.

https://doi.org/10.3847/1538-4357/ab0d93

Matsukage, K. N., Nagayo, Y., Whitaker, M. L., Takahashi, E., \& Kawasaki, T. (2013). Melting of the Martian mantle from 1.0 to 4.5 GPa. Journal of Mineralogical and Petrological Sciences, 108(4), 201-214. https://doi.org/10.2465/jmps.120820

Mayor, M., \& Queloz, D. (1995). A Jupiter-mass companion to a solar-type star. Nature, 378(6555), 355-359. https://doi.org/10.1038/378355a0

McCormick, M. P., Thomason, L. W., \& Trepte, C. R. (1995). Atmospheric effects of the Mt Pinatubo eruption. Nature, 373(6513), 399-404. https://doi.org/10.1038/373399a0

Médard, E., \& Grove, T. L. (2006). Early hydrous melting and degassing of the Martian interior. Journal of Geophysical Research, 111(E11). https://doi.org/10.1029/2006JE002742

Miozzi, F., Morard, G., Antonangeli, D., Clark, A. N., Mezouar, M., Dorn, C., et al. (2018). Equation of State of SiC at Extreme Conditions: New Insight Into the Interior of Carbon-Rich Exoplanets. Journal of Geophysical Research: Planets, 123(9), 2295-2309. https://doi.org/10.1029/2018JE005582 
manuscript submitted to JGR: Planets Special Issue Exoplanets: The Nexus of Astronomy and Geoscience

Moore, G. (2008). Interpreting H2O and CO2 Contents in Melt Inclusions: Constraints from Solubility Experiments and Modeling. Reviews in Mineralogy and Geochemistry, 69(1), 333-361. https://doi.org/10.2138/rmg.2008.69.9

Namur, O., Collinet, M., Charlier, B., Grove, T. L., Holtz, F., \& McCammon, C. (2016). Melting processes and mantle sources of lavas on Mercury. Earth and Planetary Science Letters, 439, 117-128. https://doi.org/10.1016/j.eps1.2016.01.030

Nisr, C., Meng, Y., MacDowell, A. A., Yan, J., Prakapenka, V., \& Shim, S.-H. (2017). Thermal Expansion of SiC at High Pressure-Temperature and Implications for Thermal Convection in the Deep Interiors of Carbide Exoplanets. Journal of Geophysical Research: Planets, 122(1), 124-133. https://doi.org/10.1002/2016JE005158

Ochs, F. A. I., \& Lange, R. A. (1999). The density of hydrous magmatic liquids. Science, $283,1314-1317$

O’Neill, H. S. C., \& Mavrogenes, J. A. (2002). The Sulfide Capacity and the Sulfur Content at Sulfide Saturation of Silicate Melts at $1400^{\circ} \mathrm{C}$ and 1 bar, 43(6), 39.

Oppenheimer, C., Scaillet, B., \& Martin, R. S. (2011). Sulfur Degassing From Volcanoes: Source Conditions, Surveillance, Plume Chemistry and Earth System Impacts. Reviews in Mineralogy and Geochemistry, 73(1), 363-421. https://doi.org/10.2138/rmg.2011.73.13

Owen, J. E., \& Wu, Y. (2013). Kepler Planets: A Tale of Photoevaporation. The Astrophysical Journal, 775(2), 105. https://doi.org/10.1088/0004-637X/775/2/105 
manuscript submitted to JGR: Planets Special Issue Exoplanets: The Nexus of Astronomy and Geoscience

Papale, P., Moretti, R., \& Barbato, D. (2006). The compositional dependence of the saturation surface of $\mathrm{H} 2 \mathrm{O}+\mathrm{CO} 2$ fluids in silicate melts. Chemical Geology, 229(1-3), 78-95. https://doi.org/10.1016/j.chemgeo.2006.01.013

Petigura, E. A., Howard, A. W., Marcy, G. W., Johnson, J. A., Isaacson, H., Cargile, P. A., et al. (2017). The California-Kepler Survey. I. High-resolution Spectroscopy of 1305 Stars Hosting Kepler Transiting Planets. The Astronomical Journal, 154(3), 107. https://doi.org/10.3847/1538-3881/aa80de

Plotnykov, M., \& Valencia, D. (2020). Chemical fingerprints of formation in rocky super-Earths' data. Monthly Notices of the Royal Astronomical Society, 499(1), 932-947. https://doi.org/10.1093/mnras/staa2615

Praetorius, S., Mix, A., Jensen, B., Froese, D., Milne, G., Wolhowe, M., et al. (2016). Interaction between climate, volcanism, and isostatic rebound in Southeast Alaska during the last deglaciation. Earth and Planetary Science Letters, 452, 79-89. https://doi.org/10.1016/j.epsl.2016.07.033

Putirka, K. (2016). Rates and styles of planetary cooling on Earth, Moon, Mars, and Vesta, using new models for oxygen fugacity, ferric-ferrous ratios, olivine-liquid Fe-Mg exchange, and mantle potential temperature. American Mineralogist, 101(4), 819-840. https://doi.org/10.2138/am-2016-5402

Putirka, K., Johnson, M., Kinzler, R., Longhi, J., \& Walker, D. (1996). Thermobarometry of mafic igneous rocks based on clinopyroxene-liquid equilibria, 0-30 kbar. Contributions to Mineralogy and Petrology, 123(1), 92-108.

Quick, L. C., Roberge, A., Mlinar, A. B., \& Hedman, M. M. (2020). Forecasting Rates of Volcanic Activity on Terrestrial Exoplanets and Implications for Cryovolcanic 
manuscript submitted to JGR: Planets Special Issue Exoplanets: The Nexus of Astronomy and Geoscience

Activity on Extrasolar Ocean Worlds. Publications of the Astronomical Society of the Pacific, 132(1014), 27. https://doi.org/10.1088/1538-3873/ab9504

Reid, J. C. (1985). Comparison chart for estimating volume percentages of constituents in rocks and concentrates in the range of 1.0 to 0.1 volume percent. American Mineralogist, 70(11-12), 1318-1319.

Roberts, J. H., \& Barnouin, O. S. (2012). The effect of the Caloris impact on the mantle dynamics and volcanism of Mercury. Journal of Geophysical Research, 117(E2). https://doi.org/10.1029/2011JE003876

Robock, A. (2000). Volcanic eruptions and climate. Reviews of Geophysics, 38(2), 191219. https://doi.org/10.1029/1998RG000054

Santos, A. R., Agee, C. B., McCubbin, F. M., Shearer, C. K., Burger, P. V., Tartèse, R., \& Anand, M. (2015). Petrology of igneous clasts in Northwest Africa 7034: Implications for the petrologic diversity of the martian crust. Geochimica et Cosmochimica Acta, 157, 56-85. https://doi.org/10.1016/j.gca.2015.02.023

Schwieterman, E. W., Kiang, N. Y., Parenteau, M. N., Harman, C. E., DasSarma, S., Fisher, T. M., et al. (2018). Exoplanet Biosignatures: A Review of Remotely Detectable Signs of Life. Astrobiology, 18(6), 663-708. https://doi.org/10.1089/ast.2017.1729

Soret, C. (1879). Sur L'état D'équilibre Que Prend au Point de Vue de sa Concentration une Dissolution Saline Primitivement Homohéne Dont Deux Parties Sont Portées à des Températures Différentes. Archives Des Sciences Physiques et Naturelles, $2(7), 48-61$. 
manuscript submitted to JGR: Planets Special Issue Exoplanets: The Nexus of Astronomy and Geoscience

Spaargaren, R. J., Ballmer, M. D., Bower, D. J., Dorn, C., \& Tackley, P. J. (2020). The influence of bulk composition on the long-term interior-atmosphere evolution of terrestrial exoplanets. Astronomy \& Astrophysics, 643(A44), 13.

https://doi.org/10.1051/0004-6361/202037632

Squyres, S. W., Aharonson, O., Clark, B. C., Cohen, B. A., Crumpler, L., de Souza, P. A., et al. (2007). Pyroclastic Activity at Home Plate in Gusev Crater, Mars. Science, 316(5825), 738-742. https://doi.org/10.1126/science.1139045

Stixrude, L., \& Lithgow-Bertelloni, C. (2005). Thermodynamics of mantle minerals - I. Physical properties. Geophysical Journal International, 162(2), 610-632. https://doi.org/10.1111/j.1365-246X.2005.02642.x

Taylor, J., Parmentier, V., Irwin, P. G. J., Aigrain, S., Lee, G. K. H., \& KrissansenTotton, J. (2020). Understanding and mitigating biases when studying inhomogeneous emission spectra with JWST. Monthly Notices of the Royal Astronomical Society, 493(3), 4342-4354. https://doi.org/10.1093/mnras/staa552

Terry, R. D., \& Chilingar, G. V. (1955). Summary of "Concerning some additional aids in studying sedimentary formations," by M. S. Shvetsov. Journal of Sedimentary Research, 25(3), 229-234. https://doi.org/10.1306/74D70466-2B21-11D7$8648000102 \mathrm{C} 1865 \mathrm{D}$

Treiman, A. H. (2007). Geochemistry of Venus' Surface: Current limitations as future opportunities. In L. W. Esposito, E. R. Stofan, \& T. E. Cravens (Eds.), Geophysical Monograph Series (Vol. 176, pp. 7-22). Washington, D. C.: American Geophysical Union. https://doi.org/10.1029/176GM03 
manuscript submitted to JGR: Planets Special Issue Exoplanets: The Nexus of Astronomy and Geoscience

Unterborn, C. T., \& Panero, W. R. (2019). The Pressure and Temperature Limits of Likely Rocky Exoplanets. Journal of Geophysical Research: Planets, 124(7), 1704-1716. https://doi.org/10.1029/2018JE005844

Valencia, D., O'Connell, R. J., \& Sasselov, D. D. (2006). Internal Structure of Massive Terrestrial Planets. Icarus, 181(2), 545-554. https://doi.org/10.1016/j.icarus.2005.11.021

Vander Kaaden, K. E., McCubbin, F. M., Nittler, L. R., Peplowski, P. N., Weider, S. Z., Frank, E. A., \& McCoy, T. J. (2017). Geochemistry, mineralogy, and petrology of boninitic and komatiitic rocks on the mercurian surface: Insights into the mercurian mantle. Icarus, 285, 155-168. https://doi.org/10.1016/j.icarus.2016.11.041

Wadhwa, M. (2008). Redox Conditions on Small Bodies, the Moon and Mars. Reviews in Mineralogy and Geochemistry, 68(1), 493-510. https://doi.org/10.2138/rmg.2008.68.17

Walker, D., Lesher, C. E., \& Hays, J. F. (1982). Soret separation of lunar liquid. In Lunar and Planetary Science Conference, 12th, Houston, TX, March 16-20, 1981, Proceedings, Section 1 (pp. 991-999). New York and Oxford: Pergamon Press.

Wallace, P. J., Plank, T., Edmonds, M., \& Hauri, E. H. (2015). Volatiles in Magmas. In Encyclopedia of Volcanoes (Second edition, pp. 163-183). Amsterdam; Boston: Elsevier/AP. Retrieved from 10.1016/B978-0-12-385938-9.00007-9

Wang, H. S., Liu, F., Ireland, T. R., Brasser, R., Yong, D., \& Lineweaver, C. H. (2018). Enhanced constraints on the interior composition and structure of terrestrial 
manuscript submitted to JGR: Planets Special Issue Exoplanets: The Nexus of Astronomy and Geoscience

exoplanets. Monthly Notices of the Royal Astronomical Society, 482(2), 22222233. https://doi.org/10.1093/mnras/sty2749

Watson, E., Wark, D., Price, J., \& Van Orman, J. (2002). Mapping the thermal structure of solid-media pressure assemblies. Contributions to Mineralogy and Petrology, 142(6), 640-652. https://doi.org/10.1007/s00410-001-0327-4

Webster, J. D., Goldoff, B., Sintoni, M. F., Shimizu, N., \& De Vivo, B. (2014). C-O-HCl-S-F Volatile Solubilities, Partitioning, and Mixing in Phonolitic-Trachytic Melts and Aqueous-Carbonic Vapor Saline Liquid at 200 MPa. Journal of Petrology, 55(11), 2217-2248. https://doi.org/10.1093/petrology/egu055

Weiss, L. M., Marcy, G. W., Petigura, E. A., Fulton, B. J., Howard, A. W., Winn, J. N., et al. (2018). The California-Kepler Survey. V. Peas in a Pod: Planets in a Kepler Multi-planet System Are Similar in Size and Regularly Spaced. The Astronomical Journal, 155(1), 48. https://doi.org/10.3847/1538-3881/aa9ff6

Wolszczan, A., \& Frail, D. (1992). A planetary system around the millisecond pulsar PSR1257 + 12. Nature, 355, 145-147. https://doi.org/10.1038/355145a0

Wykes, J. L., O'Neill, H. St. C., \& Mavrogenes, J. A. (2015). The Effect of FeO on the Sulfur Content at Sulfide Saturation (SCSS) and the Selenium Content at Selenide Saturation of Silicate Melts. Journal of Petrology, 56(7), 1407-1424. https://doi.org/10.1093/petrology/egv041

Young, P. A., Desch, S. J., Anbar, A. D., Barnes, R., Hinkel, N. R., Kopparapu, R., et al. (2014). Astrobiological Stoichiometry. Astrobiology, 14(7), 603-626. https://doi.org/10.1089/ast.2014.1143 
manuscript submitted to JGR: Planets Special Issue Exoplanets: The Nexus of Astronomy and Geoscience 
manuscript submitted to JGR: Planets Special Issue Exoplanets: The Nexus of Astronomy and Geoscience

\section{TABLES AND FIGURES}

Table 1

Experiment Starting Compositions [wt $\%$ ]

\begin{tabular}{|c|c|c|c|}
\hline Oxide & HEX1 & HEX2 & Earth* \\
\hline $\mathrm{SiO}_{2}$ & 42.0 & 50.82 & 45.96 \\
\hline $\mathrm{TiO}_{2}$ & 0.21 & & 0.181 \\
\hline $\mathrm{Al}_{2} \mathrm{O}_{3}$ & 4.85 & 3.76 & 4.06 \\
\hline $\mathrm{Cr}_{2} \mathrm{O}_{3}$ & 0.50 & & 0.468 \\
\hline $\mathrm{FeO}^{\mathrm{tot}}$ & 8.23 & 8.39 & 7.54 \\
\hline $\mathrm{MnO}$ & 0.15 & & 0.130 \\
\hline $\mathrm{MgO}$ & 40.04 & 32.35 & 37.78 \\
\hline $\mathrm{CaO}$ & 3.76 & 4.40 & 3.21 \\
\hline $\mathrm{Na}_{2} \mathrm{O}$ & 0.21 & 0.27 & 0.332 \\
\hline $\mathrm{K}_{2} \mathrm{O}$ & 0.05 & & 0.032 \\
\hline $\mathrm{P}_{2} \mathrm{O}_{5}$ & 0.01 & & 0.019 \\
\hline $\mathrm{NiO}$ & 0.27 & & 0.277 \\
\hline $\mathrm{Mg \#}$ & 90 & 87 & 90 \\
\hline \multicolumn{4}{|c|}{ Molar ratios } \\
\hline $\mathrm{Mg} / \mathrm{Si}$ & 1.42 & 0.95 & 1.23 \\
\hline $\mathrm{Ca} / \mathrm{Al}$ & 0.70 & 1.07 & 0.72 \\
\hline
\end{tabular}


Table 2

Piston-Cylinder Experimental Conditions and Run Products

\begin{tabular}{|c|c|c|c|c|c|c|c|c|}
\hline \multirow[t]{2}{*}{ Expt. } & \multirow[t]{2}{*}{$\mathrm{P}[\mathrm{kbar}]$} & \multirow[t]{2}{*}{$\mathrm{T}\left[{ }^{\circ} \mathrm{C}\right]$} & \multirow[t]{2}{*}{$\mathrm{t}[\mathrm{hrs}]$} & \multicolumn{5}{|c|}{ Phases $(\%)$} \\
\hline & & & & ol & opx & $\mathrm{cpx}$ & $\mathrm{sp}$ & liq \\
\hline \multicolumn{9}{|l|}{$H E X 1$} \\
\hline \multirow[t]{2}{*}{ R39* } & 20 & 1450 & 24 & o & $\mathrm{x}$ & $\mathrm{x}$ & o & o \\
\hline & & & & - & - & - & - & - \\
\hline \multirow[t]{2}{*}{ R137 } & 20 & 1400 & 24 & 71 & 1.0 & $\mathrm{x}$ & 3.4 & 25 \\
\hline & & & & 2.8 & 4.3 & - & 0.8 & 2.5 \\
\hline \multirow[t]{2}{*}{ R77 } & 20 & 1350 & 24 & 52 & 21 & 18 & 9 & $\mathrm{x}$ \\
\hline & & & & 0.6 & 1.0 & 0.7 & 0.2 & - \\
\hline \multirow[t]{2}{*}{ R44 } & 20 & 1300 & 24 & 51 & 22 & 18 & 9 & $\mathrm{x}$ \\
\hline & & & & 1.1 & 1.9 & 1.2 & 0.4 & - \\
\hline \multirow[t]{2}{*}{ R34 } & 20 & 1200 & 24 & 51 & 25 & 16 & 9 & $\mathrm{x}$ \\
\hline & & & & 0.4 & 0.7 & 0.5 & 0.2 & - \\
\hline \multirow[t]{2}{*}{ R99 } & 10 & 1375 & 24 & 70 & $\mathrm{x}$ & $\mathrm{x}$ & 4 & 27 \\
\hline & & & & 0.4 & - & - & 0.4 & 0.5 \\
\hline \multirow[t]{2}{*}{ R74 } & 10 & 1350 & 24 & 65 & $\mathrm{x}$ & $\mathrm{x}$ & 3 & 33 \\
\hline & & & & 0.6 & - & - & 0.5 & 0.7 \\
\hline \multirow[t]{2}{*}{ R80 } & 10 & 1300 & 24 & 68 & 4 & $\mathrm{x}$ & 5 & 23 \\
\hline & & & & 1.4 & 2.2 & - & 0.4 & 1.2 \\
\hline \multirow[t]{2}{*}{ R85 } & 10 & 1250 & 24 & 60 & 14 & 13 & 7 & 6 \\
\hline & & & & 4.6 & 5.6 & 3.9 & 1.2 & 5.3 \\
\hline \multirow[t]{2}{*}{ R57 } & 10 & 1200 & 24 & 53 & 23 & 16 & 8 & $\mathrm{x}$ \\
\hline & & & & 1.1 & 1.8 & 1.1 & 0.4 & - \\
\hline \multirow[t]{2}{*}{ R61 } & 10 & 1100 & 24 & 54 & 22 & 15 & 9 & $\mathrm{x}$ \\
\hline & & & & 0.5 & 0.8 & 0.5 & 0.2 & - \\
\hline \multicolumn{9}{|l|}{$H E X 2$} \\
\hline \multirow[t]{2}{*}{$\mathrm{R} 115$} & 20 & 1400 & 24 & 17 & 63 & $x$ & 1 & 18 \\
\hline & & & & 1.3 & 2.0 & - & 0.2 & 1.1 \\
\hline \multirow[t]{2}{*}{ R123 } & 20 & 1350 & 24 & 26 & 49 & $\mathrm{x}$ & 1 & 24 \\
\hline & & & & 1.7 & 2.8 & - & 0.3 & 1.6 \\
\hline \multirow[t]{2}{*}{ R132 } & 20 & 1300 & 24 & 7 & 70 & 17 & 6 & $\mathrm{x}$ \\
\hline & & & & 1.1 & 1.9 & 1.2 & 0.3 & - \\
\hline \multirow[t]{2}{*}{ R127 } & 20 & 1250 & 24 & 7 & 70 & 18 & 5 & $\mathrm{x}$ \\
\hline & & & & 0.3 & 0.6 & 0.4 & 0.0 & - \\
\hline \multirow[t]{2}{*}{ R109 } & 20 & 1150 & 24 & 6 & 69 & 19 & 6 & $\mathrm{x}$ \\
\hline & & & & 0.1 & 0.2 & 0.1 & 0.0 & - \\
\hline \multirow[t]{2}{*}{ R107 } & 20 & 1100 & 24 & 5 & 68 & 20 & 7 & $\mathrm{x}$ \\
\hline & & & & 2.8 & 4.7 & 2.9 & 0.8 & - \\
\hline \multirow[t]{2}{*}{ R117 } & 15 & 1400 & 24 & 32 & 40 & $\mathrm{x}$ & $\mathrm{x}$ & 29 \\
\hline & & & & 0.8 & 1.2 & - & - & 0.6 \\
\hline
\end{tabular}


manuscript submitted to JGR: Planets Special Issue Exoplanets: The Nexus of Astronomy and Geoscience

\begin{tabular}{|c|c|c|c|c|c|c|c|c|}
\hline \multirow[t]{2}{*}{ R129 } & 15 & 1350 & 24 & 15 & 63 & $\mathrm{x}$ & 2 & 20 \\
\hline & & & & 2.0 & 3.4 & - & 0.4 & 2.0 \\
\hline \multirow[t]{2}{*}{ R131 } & 15 & 1300 & 24 & 27 & 48 & 2.5 & 3 & 20 \\
\hline & & & & 1.0 & 1.3 & 0.8 & 0.2 & 1.1 \\
\hline \multirow[t]{2}{*}{ R114 } & 15 & 1250 & 24 & 8 & 70 & 17 & 5 & $\mathrm{x}$ \\
\hline & & & & 0.5 & 1.0 & 0.6 & 0.1 & - \\
\hline \multirow[t]{2}{*}{$\mathrm{R} 78$} & 15 & 1200 & 24 & 3 & 75 & 17 & 5 & $x$ \\
\hline & & & & 1.0 & 1.7 & 1.0 & 0.2 & - \\
\hline \multirow[t]{2}{*}{ R95 } & 15 & 1150 & 24 & 5 & 71 & 17 & 6 & $\mathrm{x}$ \\
\hline & & & & 1.2 & 2.0 & 1.2 & 0.3 & - \\
\hline \multirow[t]{2}{*}{ R110 } & 15 & 1100 & 72 & 5 & 69 & 19 & 7 & $\mathrm{x}$ \\
\hline & & & & 0.5 & 0.8 & 0.5 & 0.1 & - \\
\hline \multirow[t]{2}{*}{ R122 } & 10 & 1350 & 24 & 32 & 34 & $\mathrm{x}$ & $\mathrm{x}$ & 34 \\
\hline & & & & 1.9 & 3.0 & - & - & 1.8 \\
\hline \multirow[t]{2}{*}{ R125 } & 10 & 1325 & 24 & 22 & 47 & $\mathrm{x}$ & $\mathrm{x}$ & 31 \\
\hline & & & & 0.9 & 1.4 & - & - & 0.8 \\
\hline \multirow[t]{2}{*}{ R130 } & 10 & 1250 & 24 & 15 & 62 & 6 & 3 & 14 \\
\hline & & & & 0.5 & 0.7 & 0.5 & 0.1 & 0.7 \\
\hline \multirow[t]{2}{*}{ R135 } & 10 & 1200 & 24 & 6 & 73 & 16 & 5 & $\mathrm{x}$ \\
\hline & & & & 0.5 & 0.9 & 0.6 & 0.1 & - \\
\hline \multirow[t]{2}{*}{ R105 } & 10 & 1150 & 24 & 5 & 72 & 16 & 6 & $\mathrm{x}$ \\
\hline & & & & 1.5 & 2.4 & 1.5 & 0.4 & - \\
\hline \multirow[t]{2}{*}{ R108 } & 10 & 1100 & 72 & 6 & 67 & 17 & 7 & $\mathrm{x}$ \\
\hline & & & & 1.5 & 2.4 & 1.5 & 0.4 & - \\
\hline
\end{tabular}

Note. Complete compositional data in Supplementary Table S1. ol = olivine, opx $=$ orthopyroxene, $\mathrm{cpx}=$ clinopyroxene, $\mathrm{sp}=$ spinel, liq = liquid (glass) $\mathrm{x}=$ phase was not present, $\mathrm{o}=$ phase was present but in an experiment that was only used to confirm the solidus. Phase percentages calculated by mass balance. Italics indicate standard error for phase percentages. *R39 lost $>10 \mathrm{wt} \% \mathrm{Fe}$ and therefore was only used to confirm the solidus.

Table 3

Average Mantle Modes

\begin{tabular}{lcccc}
\hline \hline & Olivine & Opx & Cpx & Spinel \\
\hline HEX1 & $52 \%$ & $22 \%$ & $16 \%$ & $9 \%$ \\
& 1.3 & 1.4 & 1.4 & 0.48 \\
HEX2 & $6 \%$ & $71 \%$ & $17 \%$ & $6 \%$ \\
& 1.4 & 2.1 & 1.3 & 0.96 \\
Earth* & $60 \%$ & $15 \%$ & $15 \%$ & $10 \%$ \\
\hline $\begin{array}{l}\text { Note. Italics indicate standard error. *The undepleted Earth } \\
\text { mantle composition of Hart \& Zindler (1986) is given as a } \\
\text { reference. }\end{array}$
\end{tabular}


manuscript submitted to JGR: Planets Special Issue Exoplanets: The Nexus of Astronomy and Geoscience

Table 4

Experimentally Determined Melting Reactions

\begin{tabular}{lcl}
\hline \hline & P [kbar $]$ & Melting reaction \\
\hline HEX1 & 10 & $0.54 \mathrm{cpx}+0.68 \mathrm{opx}+0.16 \mathrm{sp} \rightarrow 0.39 \mathrm{ol}+1.0$ melt \\
& 20 & $0.73 \mathrm{cpx}+0.79 \mathrm{opx}+0.24 \mathrm{sp} \rightarrow 0.77 \mathrm{ol}+1.0$ melt \\
HEX2 & 10 & $0.46 \mathrm{cpx}+1.04 \mathrm{opx}+0.17 \mathrm{sp} \rightarrow 0.68 \mathrm{ol}+1.0$ melt \\
& 15 & $0.65 \mathrm{cpx}+0.83 \mathrm{opx}+0.14 \mathrm{sp} \rightarrow 0.63 \mathrm{ol}+1.0$ melt \\
& 20 & $0.96 \mathrm{cpx}+0.39 \mathrm{opx}+0.23 \mathrm{sp} \rightarrow 0.58 \mathrm{ol}+1.0$ melt \\
Earth* & 9 & $0.31 \mathrm{cpx}+0.16 \mathrm{opx}+0.58 \mathrm{sp} \rightarrow 0.06 \mathrm{ol}+1.0$ melt
\end{tabular}

Note. *Anhydrous undepleted lherzolitic mantle (Kinzler \& Grove, 1992a) is given as a reference.

Table 5

Average Experimental Melt Compositions [wt \%]

\begin{tabular}{lcccl}
\hline \hline Oxide & HEX1 & s.d. & HEX2 & s.d. \\
\hline $\mathrm{SiO}_{2}$ & 48.09 & 1.74 & 52.88 & 1.48 \\
$\mathrm{TiO}_{2}$ & 0.86 & 0.17 & & \\
$\mathrm{Al}_{2} \mathrm{O}_{3}$ & 15.65 & 1.67 & 9.31 & 0.57 \\
$\mathrm{Cr}_{2} \mathrm{O}_{3}$ & 0.10 & 0.04 & & \\
$\mathrm{FeO}^{\text {tot }}$ & 11.16 & 1.22 & 13.64 & 0.92 \\
$\mathrm{MnO}$ & 0.18 & 0.02 & & \\
$\mathrm{MgO}$ & 9.17 & 4.45 & 9.58 & 2.69 \\
$\mathrm{CaO}$ & 13.92 & 1.65 & 13.75 & 1.28 \\
$\mathrm{Na} 2 \mathrm{O}$ & 0.68 & 0.10 & 0.84 & 0.09 \\
$\mathrm{~K} 2 \mathrm{O}$ & 0.17 & 0.02 & & \\
$\mathrm{P}_{2} \mathrm{O} 5$ & 0.01 & 0.01 & & \\
$\mathrm{NiO}$ & 0.02 & 0.02 & & \\
& & & & \\
$\mathrm{Mg} \#$ & 57.07 & 9.09 & 54.03 & 6.60 \\
$n$ points & 81 & & 174 & \\
$n$ expts & $5 *$ & & $8^{\dagger}$ & \\
\hline
\end{tabular}

Note. Compositional data determined by EPMA.

*Experiments averaged for HEX1 melt composition:

R137, R99, R74, R80, R85. "Experiments averaged for HEX2 melt composition: R115, R123, R117, R129,

R131, R122, R125, R130. 


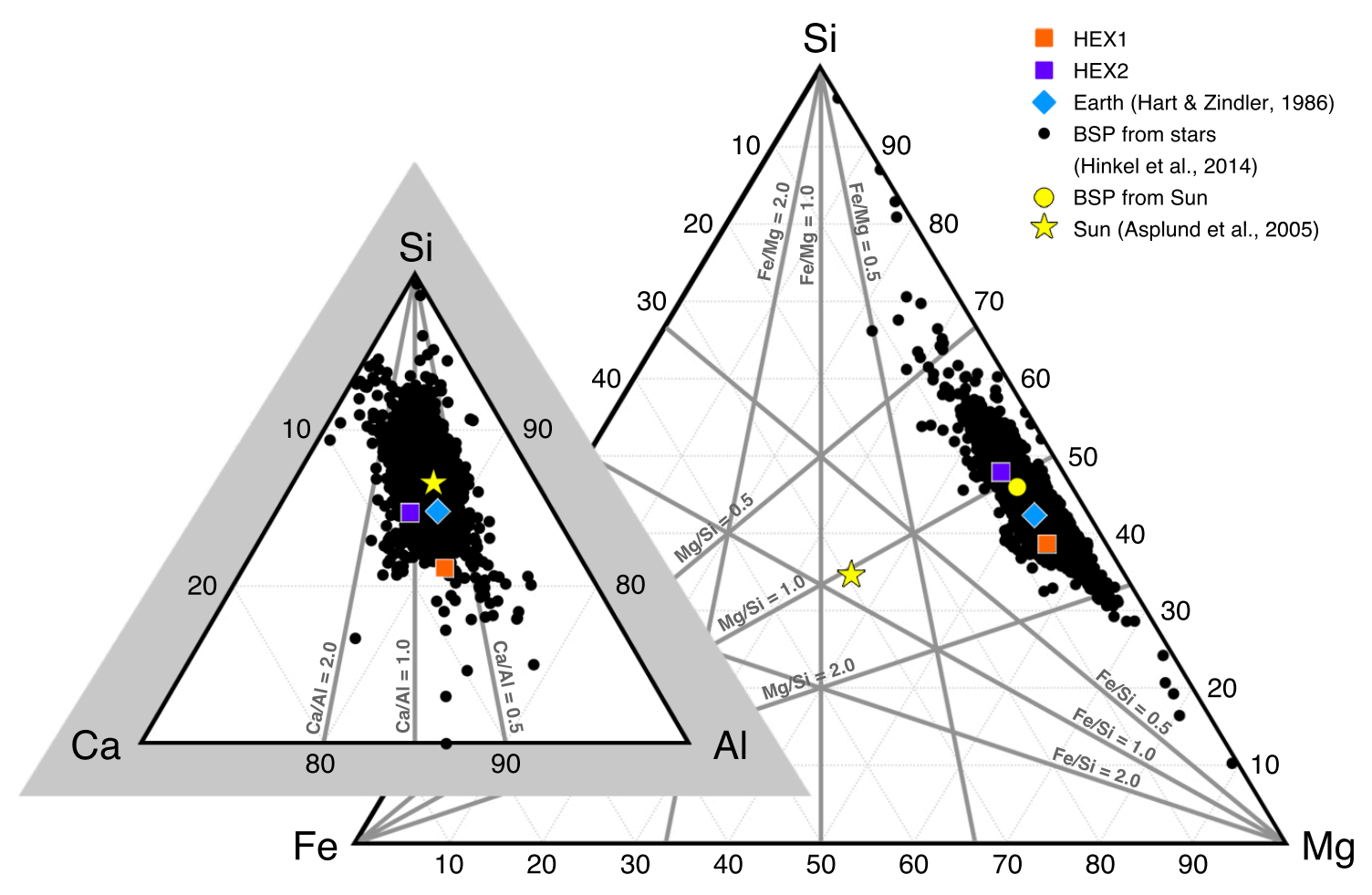

Figure 1. Ternary diagram of molar abundances of Fe, Si, and $\mathrm{Mg}$. Inset: The top vertex of a ternary diagram of molar abundances of $\mathrm{Ca}, \mathrm{Si}$, and $\mathrm{Al}$ (note the different axes). Black circles show the hypothetical bulk silicate planets (BSP) calculated from a sample of 3800 FGK-type stars in our galaxy with characterized spectra, as normalized in the Hypatia Catalog (Hinkel et al., 2014; Lodders et al., 2009). Errors for these data vary; see Hinkel et al. (2016) for further discussion. The yellow circle shows the BSP calculated from the Sun (yellow star; Asplund et al., 2005). In the composition space of the inset, the Sun and the solar BSP are the same. To generate the BSPs, $85 \%$ of the star's Fe budget was sequestered to the hypothetical exoplanet core, leaving $15 \%$ of the Fe in the BSP. This quantity was selected to produce a solar BSP with an $\mathrm{Fe} / \mathrm{Mg}$ ratio similar to that of the Earth's undepleted bulk mantle (blue diamond; Hart \& Zindler, 1986). Solid gray lines show lines of equal molar ratio. 
A

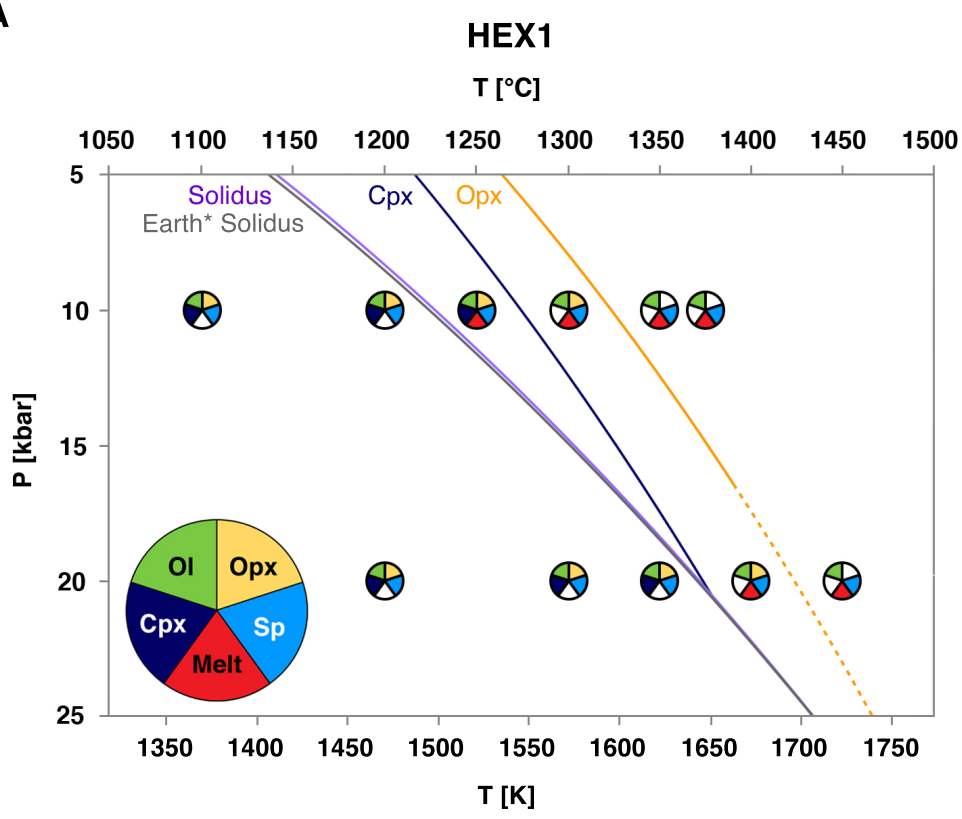

B

HEX2

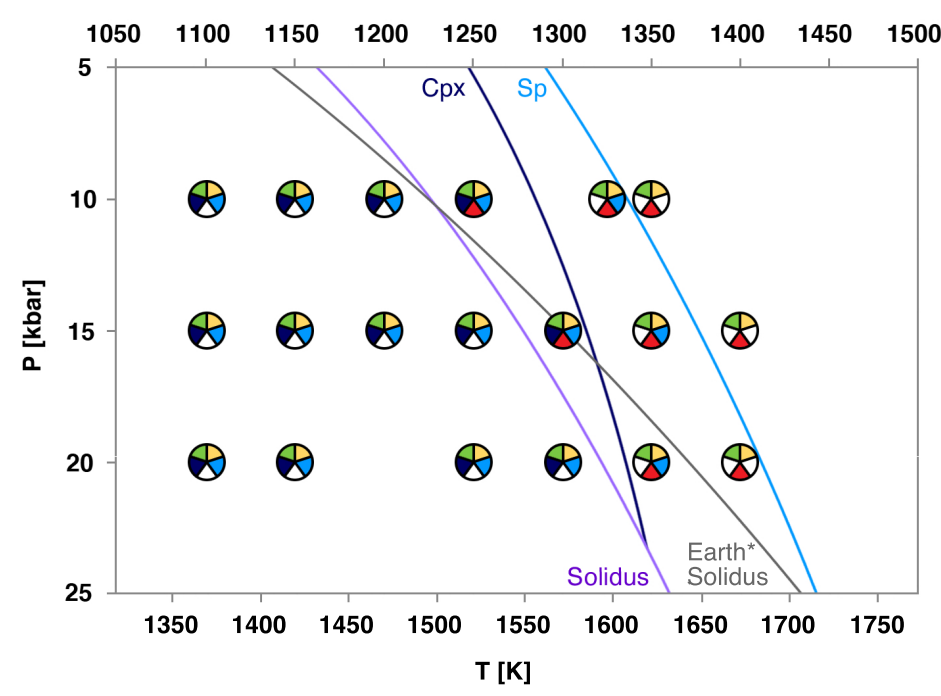

Figure 2. Phase diagrams for A: HEX1 and B: HEX2. Wedges are filled if that phase was present in that experiment. *Earth's nominally anhydrous undepleted mantle solidus is plotted in gray for reference (Hirschmann, 2000). ol = olivine, opx = orthopyroxene, $\operatorname{cpx}=$ clinopyroxene, $\mathrm{sp}=$ spinel 


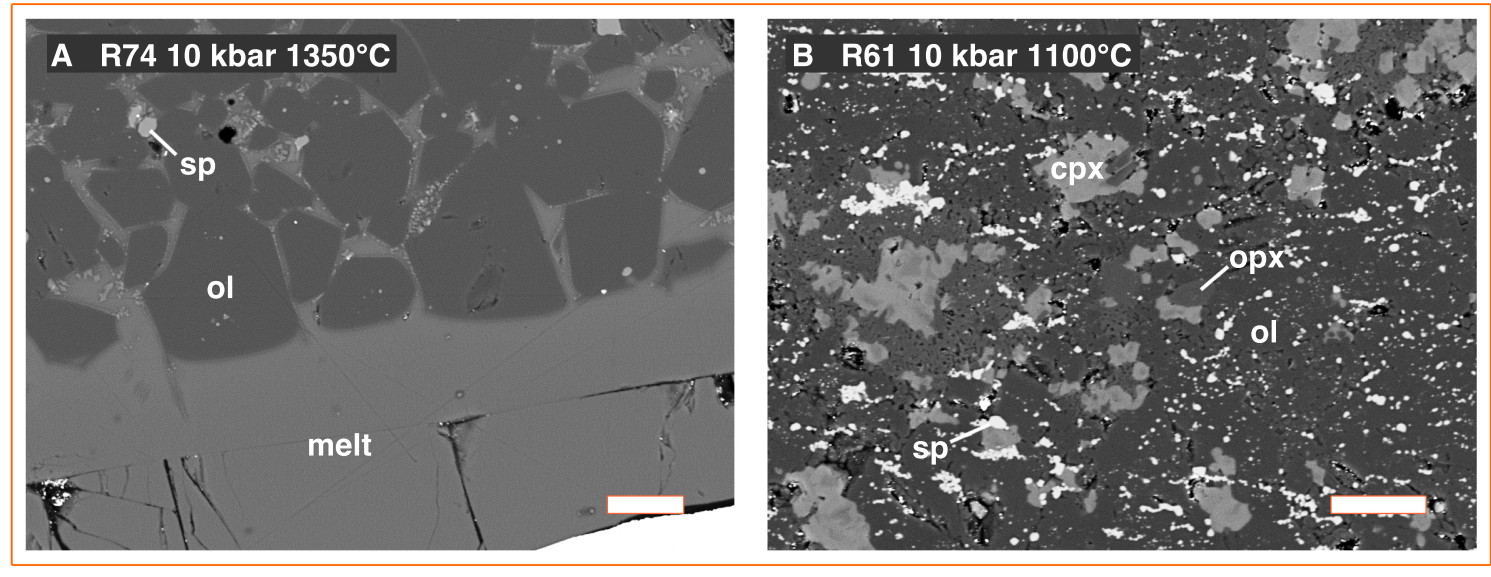

HEX2

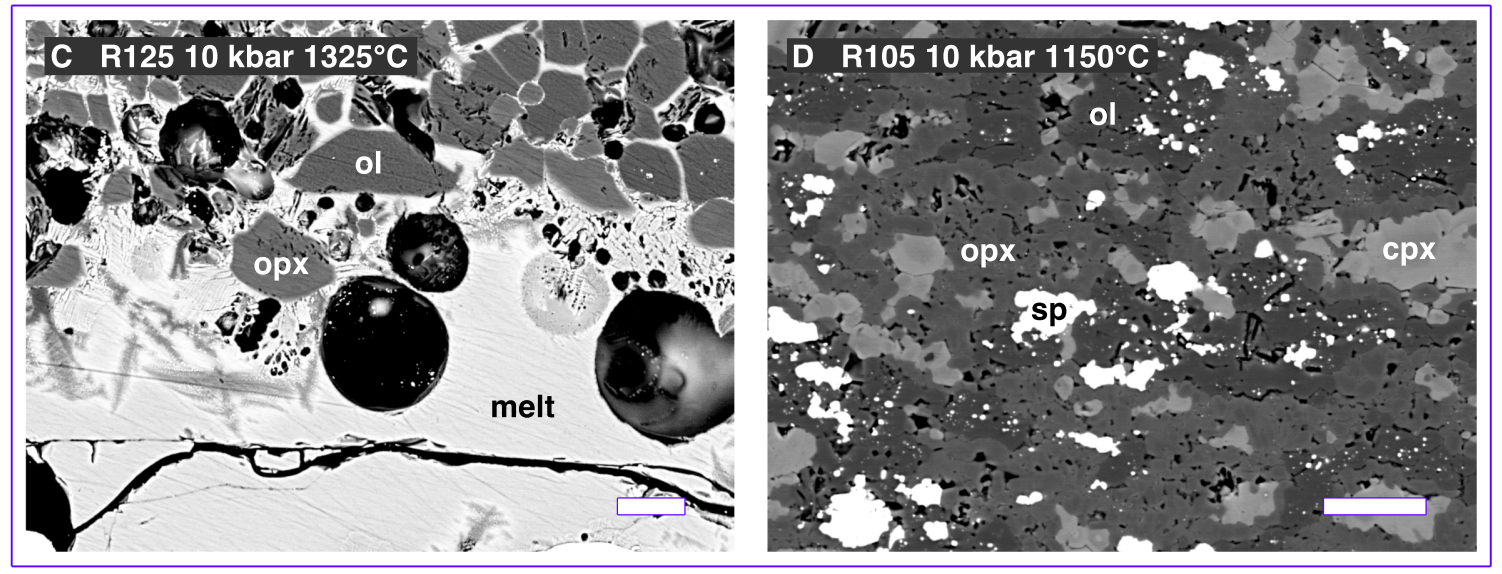

Figure 3. Backscattered electron images of $\operatorname{HEX} 1(\mathbf{A}, \mathbf{B})$ and $\operatorname{HEX} 2(\mathbf{C}, \mathbf{D})$ experiments. $\mathbf{A}$ and $\mathbf{C}$ are above the solidus and $\mathbf{B}$ and $\mathbf{D}$ are below. Scale bars are $20 \mu \mathrm{m} . \mathrm{ol}=$ olivine, opx $=$ orthopyroxene, $\mathrm{cpx}=$ clinopyroxene, $\mathrm{sp}=$ spinel 


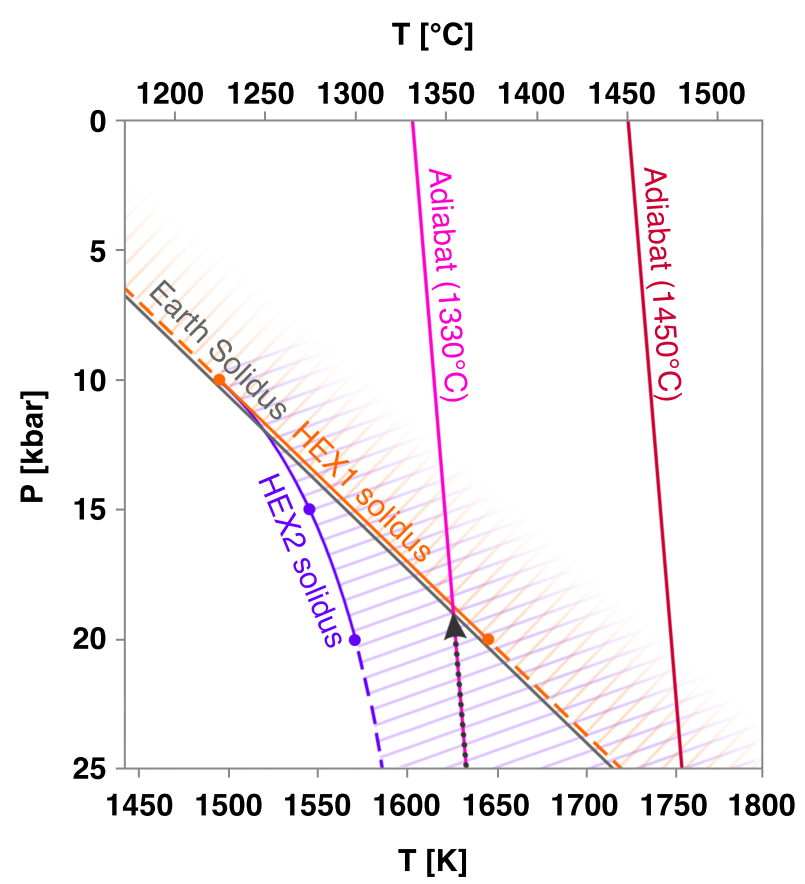

Figure 4. Pressure-temperature space showing the location of Earth's nominally anhydrous undepleted mantle solidus (Hirschmann, 2000), as well as the solidi for HEX1 and HEX2 (solid lines over the range of experimental conditions, dashed where extrapolated). The side of the solidus where melt can exist is colored. Modern-day Earth adiabats are shown pinned to bracketing mantle potential temperature $\left(T_{p o t}\right)$ estimates (1330 and $1450^{\circ} \mathrm{C}$; Putirka, 2016). The arrow indicates a sample decompression melting path that intersects the Earth and HEX1 solidus but will not intersect the HEX2 solidus as extrapolated here. 
HEX1

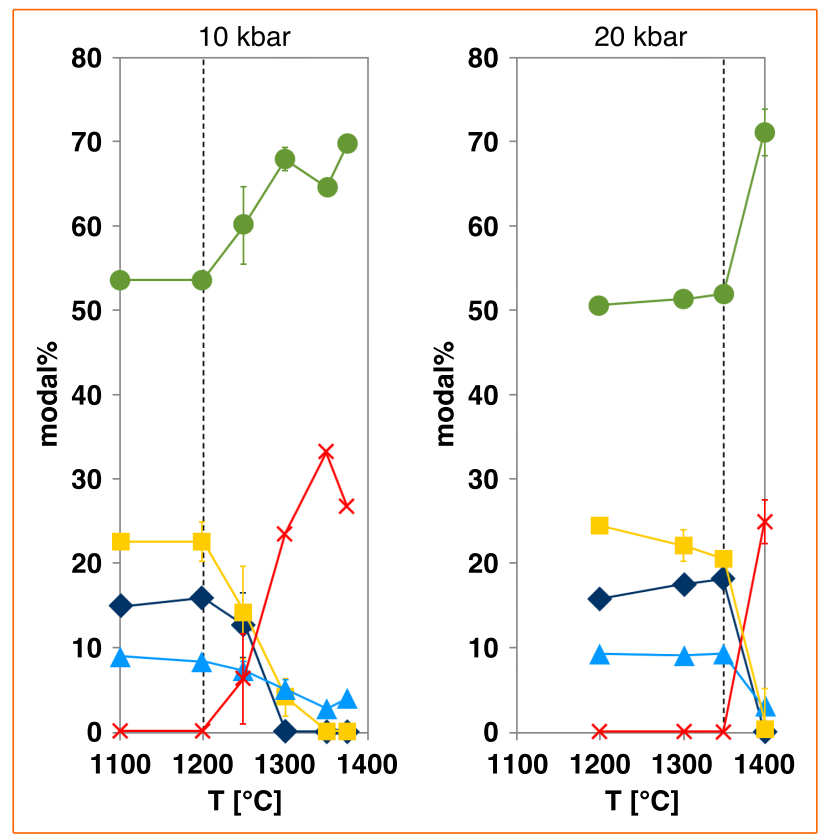

ol

opx

$\diamond \mathrm{cpx}$

$\Delta \mathrm{sp}$

$\times$ melt
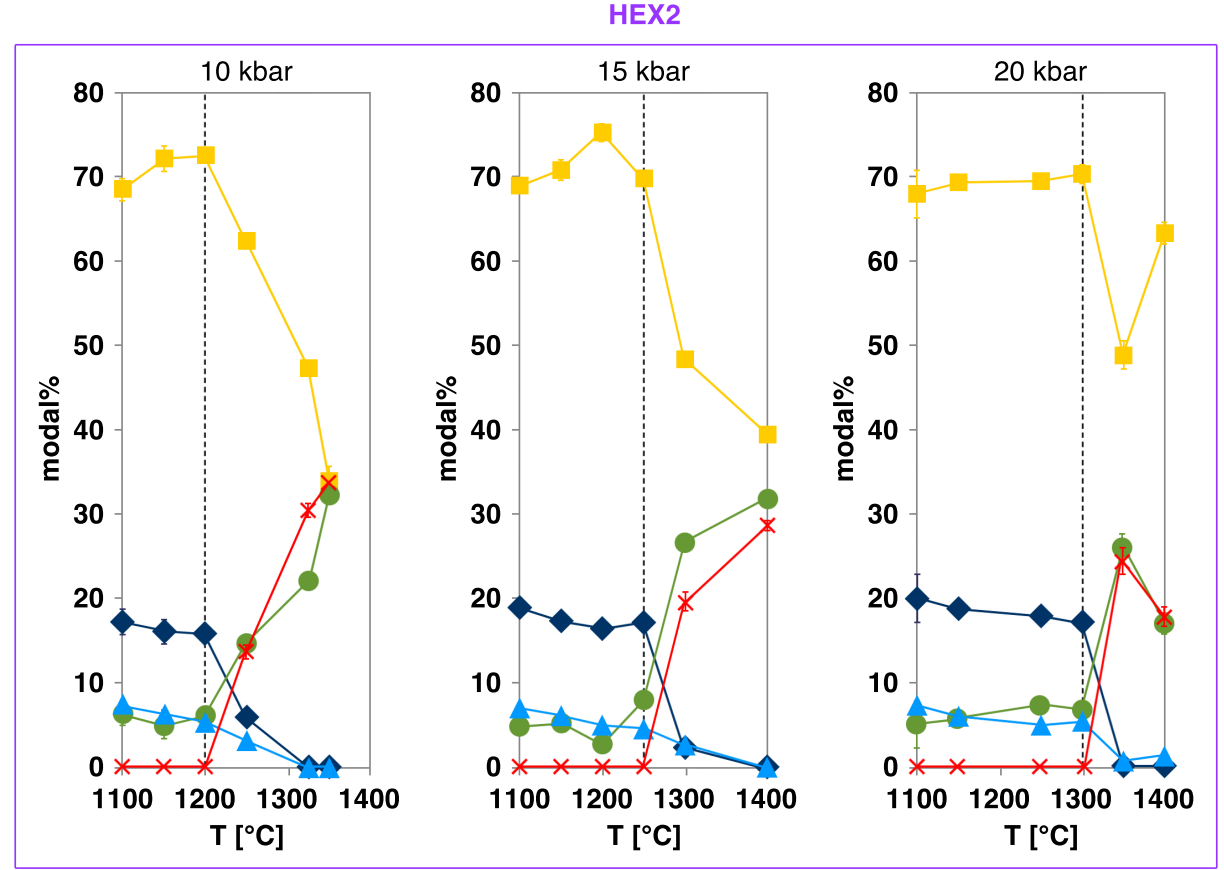

Figure 5. Plots of modal\% vs. T for HEX1 and HEX2 experiments. Note the sharp change in mineral abundance when melting begins at the solidus (dashed line). Error bars indicate 1 sigma error; some are smaller than the symbols. 


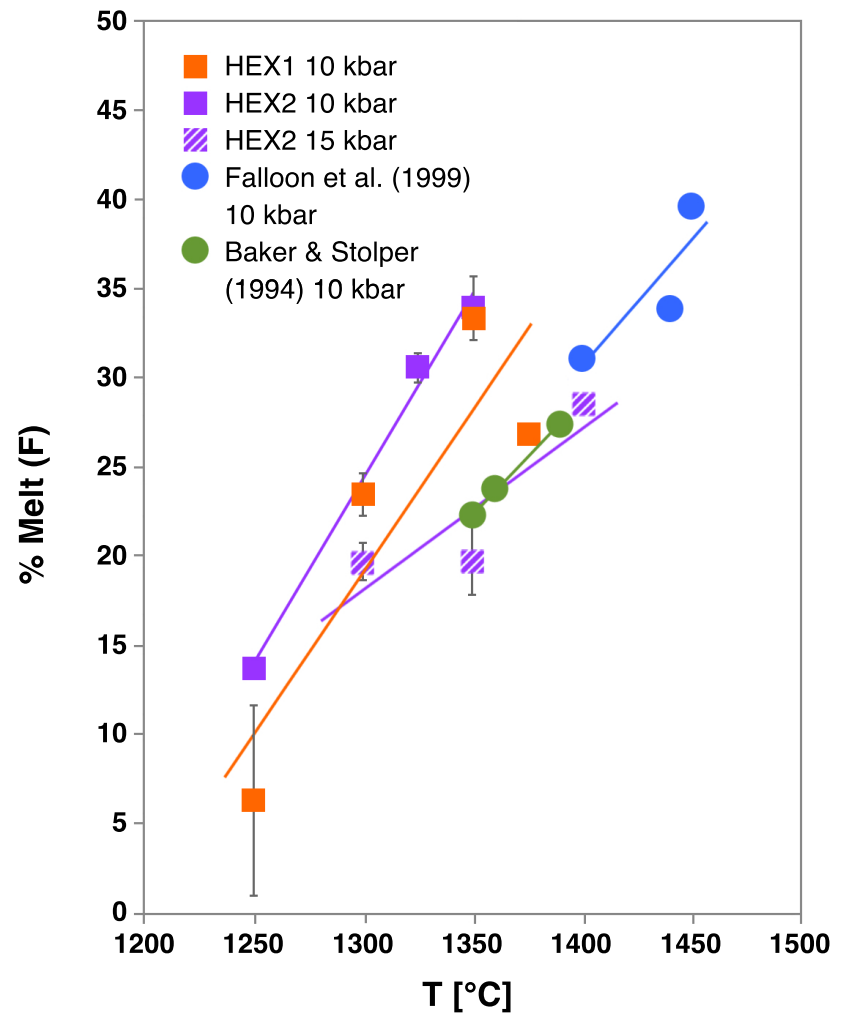

Figure 6. Plot showing percent melt $(\mathrm{F})$ per ${ }^{\circ} \mathrm{C}$ for $\mathrm{HEX} 1, \mathrm{HEX} 2$, and experiments on an undepleted Earth mantle composition (Baker \& Stolper, 1994; Falloon et al., 1999) that approximates the bulk silicate Earth composition of Hart and Zindler (1986). Error bars indicate 1 sigma error; some are smaller than the symbols. 

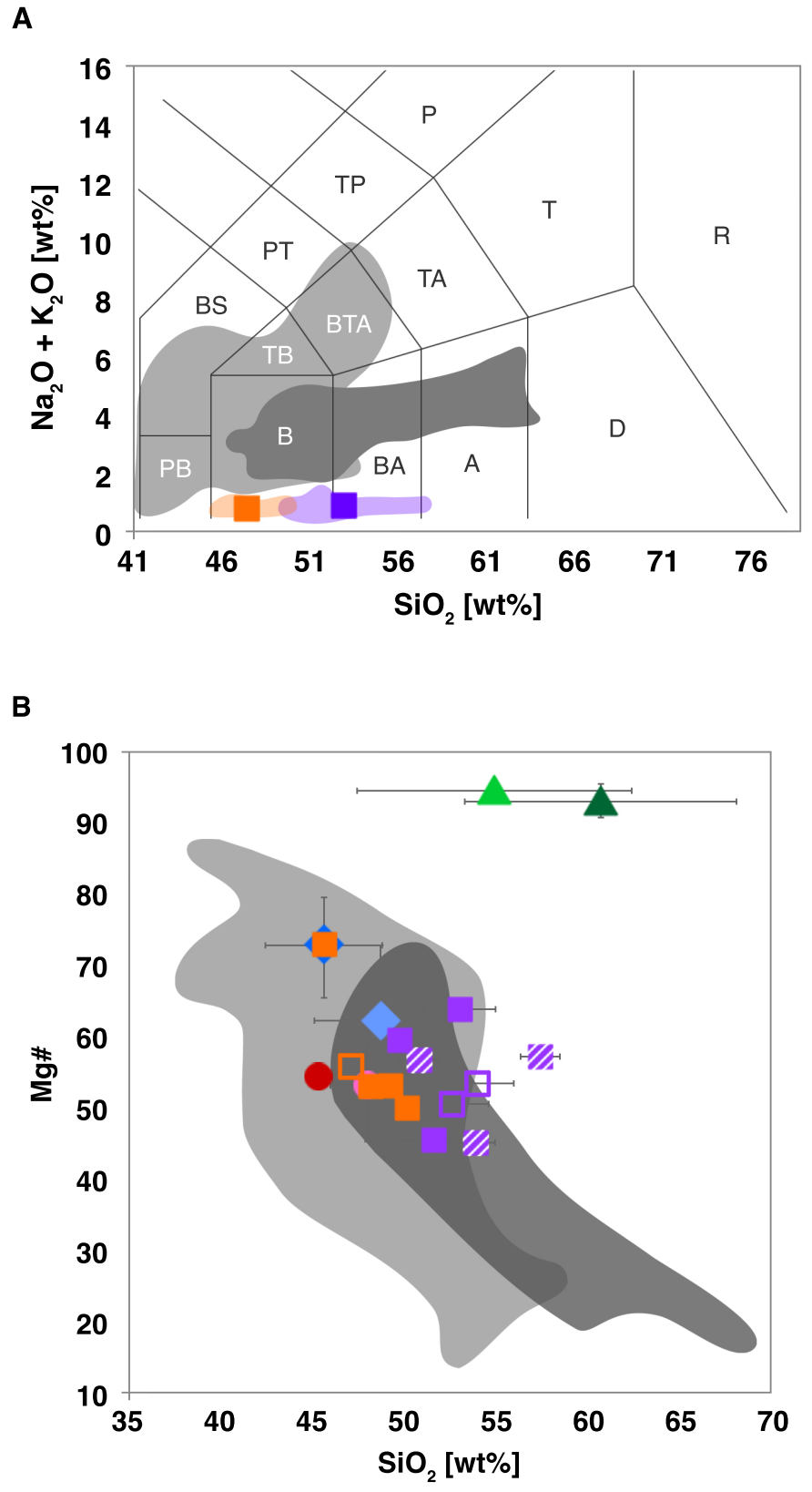


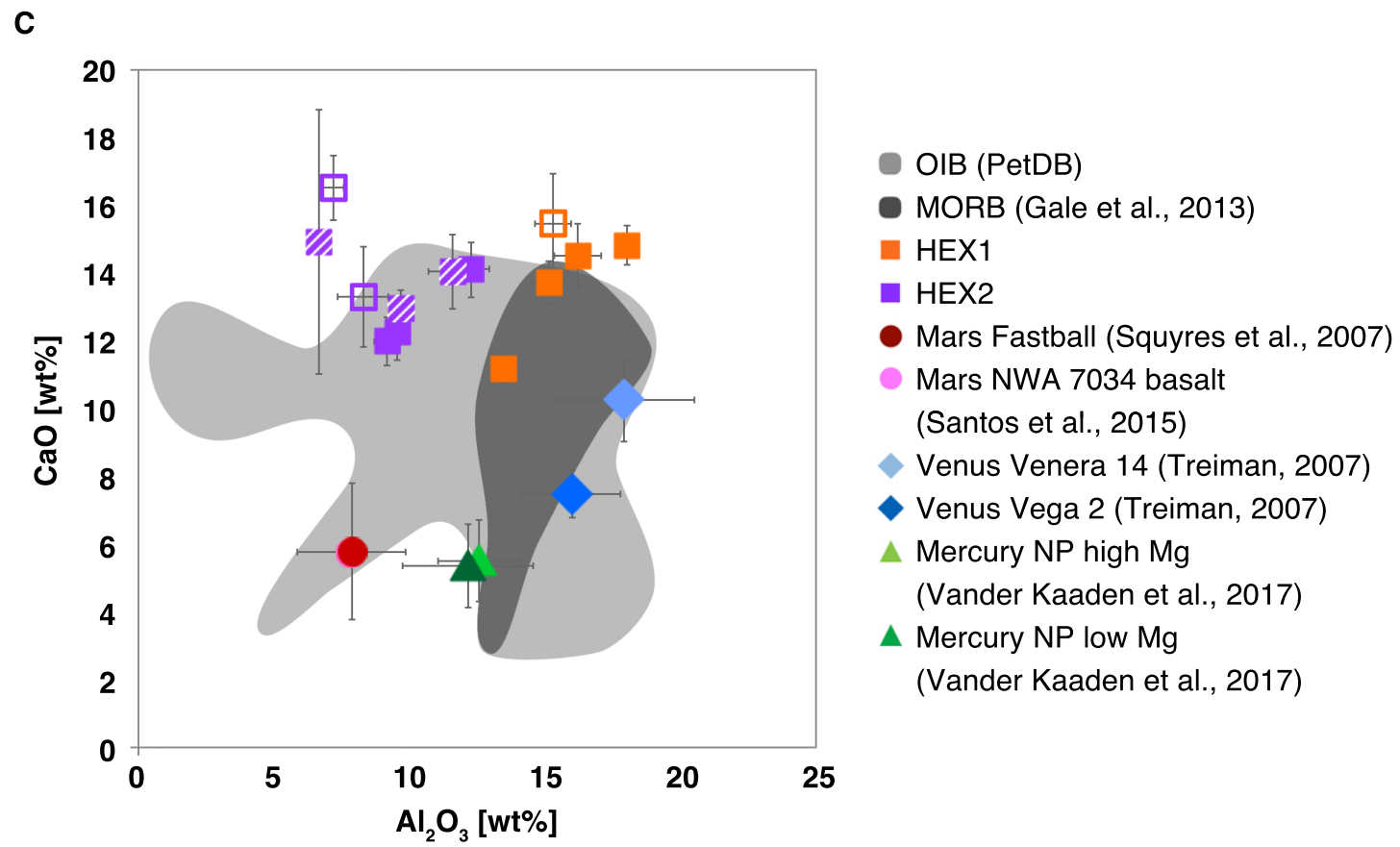

Figure 7. Composition of experimental exoplanet melts, Earth ocean island basalts (OIB, PetDB https://search.earthchem.org) and mid-ocean ridge basalts (MORB; Gale et al., 2013), and rocky solar system planet melts (Santos et al., 2015; Squyres et al., 2007; Treiman, 2007; Vander Kaaden et al., 2017). A: Total alkalis vs. $\mathrm{SiO}_{2}$, B: $\mathrm{Mg} \#$ vs. $\mathrm{SiO}_{2}$, and $\mathbf{C}: \mathrm{CaO}$ vs $\mathrm{Al}_{2} \mathrm{O}_{3}$. In panel $\mathbf{A}$, colored shaded regions indicate the compositional extent of the experimental exoplanet melts and filled squares indicate the average for each starting composition's melt. $\mathrm{P}=$ phonolite, $\mathrm{TP}=$ tephriphonolite, $\mathrm{PT}=$ phonotephrite, $\mathrm{BS}=$ basanite, $\mathrm{TB}=$ trachybasalt, $\mathrm{BTA}=$ basaltic trachyandesite, $\mathrm{TA}=$ trachyandesite, $\mathrm{T}=$ trachyte, $\mathrm{R}=$ rhyolite, $\mathrm{PB}=$ picrobasalt, $\mathrm{B}=$ basalt, $\mathrm{BA}=$ basaltic andesite, $\mathrm{A}=$ andesite, $\mathrm{D}=$ dacite. In panels $\mathbf{B}$ and $\mathbf{C}$, for HEX1 and HEX2, open symbols $=20$ kbar experiments, diagonal-barred symbols $=15 \mathrm{kbar}$ experiments, and filled symbols $=10$ kbar experiments. Error bars indicate 1 sigma error; some are smaller than the symbols. 